\title{
Heterogeneous Policy Distortions and the Labor Share
}

\section{Gabriel Smagghue ${ }^{1}$}

January 2021, WP \#803

\begin{abstract}
I develop an extension of the neoclassical growth model in which firms are heterogeneous both in terms of labor share and productivity. In this model, distortions in the allocation of resources across firms can impact the labor share of national income. Using administrative firm-level data to calibrate the model, I show in particular that a removal of policies reducing the output price of more productive firms can generate a sizable decrease in the aggregate labor share (between 1 and 4 percentage points). My results suggest that the recent decline in the global labor share of income is both qualitatively and quantitatively consistent with an improvement in resource allocation across firms.
\end{abstract}

Keywords: Labor Share; Size-based Policy; Productivity-based Policy; Resource Misallocation; Heterogeneous Labor Intensity.

JEL classification: E23, E25, H23, J23

\footnotetext{
${ }^{1}$ Banque de France, gabriel.smagghue@banque-france.fr
} 


\section{NON-TECHNICAL SUMMARY}

Government policies that impose unequal constraints across firms are widespread. Be it among policymakers or academics, these policies are suspected of having large damaging macroeconomic effects, particularly in terms of aggregate productivity and output. In this paper, I investigate the impact of heterogeneous policy distortions on a another major macroeconomic outcome: the labor share of income.

The concept of heterogeneous policy distortions spans a wide range of policies, from trade policy to fiscal policy or labor market regulation. My analysis of the link between this type of distortions and the labor share rests upon a simple empirical regularity: bigger firms tend to have a smaller labor share. Consequently, any policy limiting the weight of bigger firms in the economy potentially causes a redistribution of national income towards labor. The main contribution of this paper is to show that this composition effect can be substantial, which contributes to our general understanding of the determinants of the labor share.

In order to assess the quantitative importance of heterogeneous policy distortions for the labor share, I propose an extension of the neoclassical growth model with two-way heterogeneity across firms. In the steady-state, firm-level production functions vary both in terms of total factor productivity (TFP) and of factor elasticity. I calibrate the model using French production data for the period 1995-2007. In particular, I set the level of correlation between the two idiosyncratic technological parameters so as to match the observed correlation between size and the labor share across firms. Then, I study the impact of policies which create dispersion across firms in terms of output price or factor price. By distorting the allocation of productive resources, such policies can impact the weight of capitalintensive firms in the economy. This results in a distortion of the aggregate relative demand for capital and labor which, ultimately, impacts the labor share of national income.

My results show that considering labor share differences across firms to quantify the impact of heterogeneous distortions is primordial in the case of output price distortions. Taxing the output of the $50 \%$ most productive firms results in an increase of the national labor share ranging from 1 percentage point (hereafter "p.p.") to 2 p.p., for tax rates from $10 \%$ to $50 \%$. These effects double when I take into account selection, that is the fact that taxing productive firms allows some unproductive firms with high labor share to survive in the economy. To put these numbers in perspective, the labor share in France was 5 p.p. larger than in the US in 2005.5 p.p. also corresponds to the global drop in the labor share over the past 30 years, as estimated by Karabarbounis and Neiman (2014). My simulations suggest that the removal of productivity-based output distortions could explain from $20 \%$ to $75 \%$ of this evolution.

The mechanism presented in this paper is important for understanding what movements in the labor share can tell us about economic efficiency. There is evidence that the global decline in the labor share observed over the last decades results from an increase in average markups (De Loecker and Eeckhout, 2017, 2018), and thus potentially a loss of economic efficiency. On the contrary, my results suggest that this decline is consistent, both qualitatively and quantitatively, with a better allocation of resources towards large firms over time. 


\section{Size versus labor share across French firms}

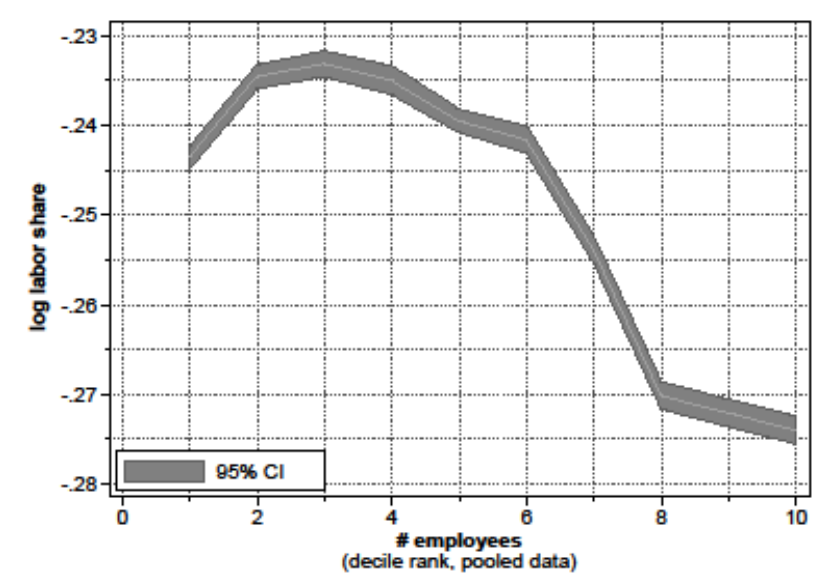

Note: This figure is constructed using firm-level information from the BRN dataset over the period 19952007. It depicts the cross-sectional relationship between firm size and the average log labor share of value added.

\section{Distorsions politiques hétérogènes et part du travail}

\section{RÉSUMÉ}

Je développe une extension du modèle de croissance néoclassique dans lequel les entreprises sont hétérogènes à la fois en termes de part du travail et de productivité. Dans ce modèle, des distorsions politiques dans l'allocation des ressources entre les entreprises peuvent avoir un impact substantiel sur la part du travail dans le revenu national. En utilisant des données administratives d'entreprises pour calibrer le modèle, je montre en particulier que le fait de retirer une taxe sur la production des entreprises plus productives peut générer une diminution importante de la part globale du travail (entre 1 et 4 points de pourcentage). Mes résultats suggèrent que le récent déclin de la part globale du travail dans le revenu est à la fois qualitativement et quantitativement cohérent avec une amélioration de l'allocation des ressources entre les entreprises.

Mots-clés : part du travail ; politique basée sur la productivité ; politique basée sur la taille; mauvaise allocation des ressources ; intensité travaillistique hétérogène 


\section{Introduction}

Government policies that impose unequal constraints across firms are widespread. Be it among policymakers or academics, these policies are suspected of having large damaging macroeconomic effects, particularly in terms of aggregate productivity and output. In this paper, I investigate the impact of heterogeneous policy distortions on a another major macroeconomic outcome: the labor share of income.

Figure 1: Size versus Labor Share across French Firms

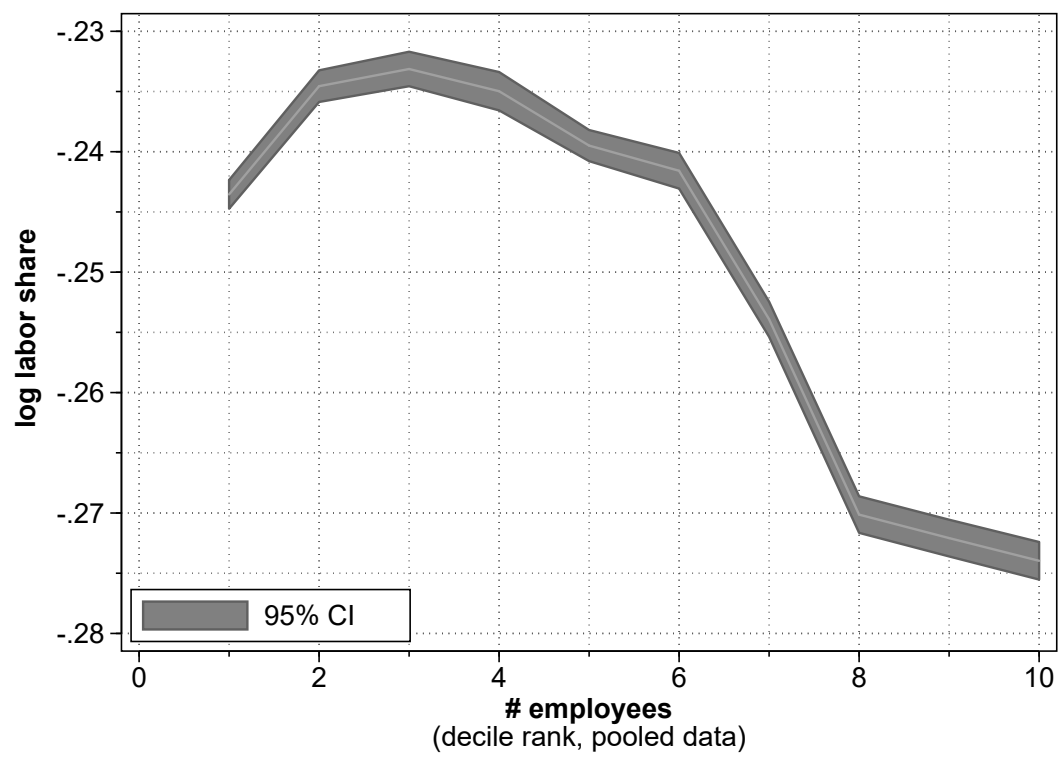

Notes: This figure is constructed using firm-level information from the BRN dataset for all sectors over the period 1995-2007. See section 2 of the main text for details on sample construction.

The concept of heterogeneous policy distortions includes a wide range of policies, from trade policy to fiscal policy or labor market regulation (see Restuccia and Rogerson (2017) for a review). The link between this type of distortions and the labor share rests upon a simple fact: bigger firms tend to have a smaller labor share (see Raval 2011 for evidence from the US, GouinBonenfant 2018 for Canada as well as Figure 1 for France). Consequently, any policy limiting the weight of bigger firms in the economy potentially causes a redistribution of national income towards labor. The main contribution of this paper is to show that this composition effect can be substantial, which contributes to our general understanding of the determinants of the labor share.

Many of the determinants suggested in the literature explain aggregate changes in the labor share through changes happening within firms. ${ }^{1}$ However, there is growing evidence that the bulk of changes in the labor share happens between firms rather than within firms. More specifically,

\footnotetext{
1 Blanchard and Giavazzi (2003) study the role of labor market deregulation, Karabarbounis and Neiman (2013) emphasize the importance of the price of capital goods. Elsby et al. (2013) and Salomons and Autor (2018) respectively focus on the role of offshoring and robotization.
} 
it appears that most of the well documented decline in the global labor share results from a redistribution of market shares toward large, low-labor share firms Autor et al. 2017; Kehrig and Vincent 2017). The literature has not yet reached a consensus as to what mechanism has caused this redistribution. Autor et al. (2017) hint at the role of technology and globalisation. Lashkari et al. (2018) document the role of the fall in the price of Information Technology capital goods. Gouin-Bonenfant (2018) points to the effect of productivity dispersion. In this paper, I provide simulation-based evidence that heterogeneous policy distortions, by redistributing resources across firms, can cause substantial changes in the aggregate labor share.

More specifically, my results show that considering labor share differences across firms to quantify the impact of heterogeneous distortions is primordial in the case of output price distortions, but not so much in the case of factor price distortions. Intuitively, this is because in the case of factor price distortion, most of the factor income redistribution happens within firms, as they adjust their capital-labor mix. There is no need to model labor share differences across firms to quantify this effect. By constrast, in the case of output distortion, factor income redistribution happens between firms, as market shares get redistributed across high and low labor share firms. To quantify this between-firm factor substitution, it is vital to have a model with heterogeneous labor shares.

The mechanism presented in this paper is important for understanding what movements in the labor share can tell us about economic efficiency. There is evidence that the global decline in the labor share observed over the last decades results from an increase in average markups (De Loecker and Eeckhout, 2017, 2018), and thus potentially a loss of economic efficiency. On the contrary, my results suggest that this decline is consistent, both qualitatively and quantitatively, with a better allocation of resources towards large firms over time. In this sense, the mechanism I propose to rationalize the decline in the labor share is reminiscent of the improvement of allocative efficiency documented by Baqaee and Farhi (2020) for the US over the period 19972015.

In order to assess the quantitative importance of heterogeneous policy distortions for the labor share, I propose an extension of the neoclassical growth model with two-way heterogeneity across firms. In the steady-state, firm-level production functions vary both in terms of total factor productivity (TFP) and of factor elasticity. My model is therefore a generalization of Restuccia and Rogerson (2008) to the case of non-Hicks neutral technological differences across firms. I calibrate the model using French production data for the period 1995-2007. In particular, I set the level of correlation between the two idiosyncratic technological parameters so as to match the observed correlation between size and the labor share across firms. Then, I study the impact of policies which create dispersion across firms in terms of output price or factor price. By distorting the allocation of productive resources, such policies can impact the weight of capital-intensive firms in the economy. This results in a distortion of the aggregate relative demand for capital and labor which, ultimately, impacts the labor share of national income.

I model policy distortions as heterogeneous tax (or subsidy) rates across firms. I consider three types of tax: on output, on capital and on labor. Of the three, the tax on output is probably the best to showcase the role of labor share heterogeneity across firms. Indeed, an output tax does not impact the labor share of taxed firms because it does not distort their relative factor costs. Therefore, the only way a productivity-based output tax will impact the aggregate labor share is by reallocating market shares across firms with different labor shares. By contrast, heterogeneous tax rates on capital or labor will impact the aggregate labor share 
through a combination of within-firm factor substitution (taxed firm change their mix of capital and labor) and between-firm factor substitution (market shares get reallocated toward high labor share firms). My simulations will allow me to get at the relative magnitude of these two effects.

I consider two complementary strategies to calibrate the policy distortions. First, I study a class of hypothetical distortions which consist in firm-specific implicit tax/subsidy. These generic policy distortions are simple and flexible. By considering different distributions of tax and subsidy rates across firms, I am able to trace out the general relationship between productivitybased distortions and the labor share. Second, I study the case of a real-world size-dependent regulation: the 50 employees threshold in France. As French firms exceed this threshold, they must provide their workers with multiple additional rights. ${ }^{2}$

My results suggest that the effects of heterogeneous output distortions can be sizable. Taxing the $50 \%$ most productive firms results in an increase of the national labor share ranging from 1 percentage point (hereafter "p.p.") to 2 p.p, for tax rates from $10 \%$ to $50 \%$. These effects double when I take into account selection, that is the fact that taxing productive firms allows some unproductive firms with high labor share to survive in the economy. To put these numbers in perspective, the labor share in France was 5 p.p. larger than in the US in 2005. 5 p.p. also corresponds to the global drop in the labor share over the past 30 years, as estimated by Karabarbounis and Neiman (2014). My simulations suggest that the removal of productivitybased output distortions could explain from $20 \%$ to $75 \%$ of this evolution.

When it comes to capital price distortion, I find a large labor share response, from 1.6 to 5.8 p.p. Nevertheless, most of this effect is due to taxed firms substituting labor for capital (the within-firm substitution effect). By contrast, the reallocation of market shares from low to high labor share firms (the between-firm substitution effect) has a marginal contribution. This suggests that it is not crucial to take into account labor share differences across firms to quantify the labor share impact of heterogeneous capital distortions.

The same message emerges from simulating the removal of the 50 employees threshold. I find that this removal increases the labor share by 0.4 p.p. This means that the within-firm effect (previously regulated firms substitute labor for capital) dominates the between-firm effect (productive/low labor share firms expand in the economy).

Although this paper mainly adds to the labor share literature, it also contributes to other lines of research. First, it relates to the literature on the macroeconomic effects of heterogeneous policy distortions across firms, initiated by Restuccia and Rogerson $(2008)$ and Hsieh and Klenow (2009). ${ }^{3}$ Many papers study the special case of size-dependent distortions (Guner et al. 2008; Braguinsky et al. 2011; Garcia-Santana and Pijoan-Mas 2014) both because they are widespread and suspected to be particularly distortionary. The general message of this literature is that resource misallocation caused by heterogeneous distortions can explain a large share of productivity differences across countries. By contrast, this paper is the first to propose a general study of the link between heterogeneous policy distortions and factor income distribution.

\footnotetext{
2 Garicano et al. (2016) and Gourio and Roys (2014) also look at the macroeconomic effects of the 50 threshold in France but they ignore factor intensity differences across firms, as they focus on the consequences in terms of output rather than factor income distribution (Gourio and Roys 2014 Garicano et al. 2016). These papers get to the conclusion that, because regulation hinders labor demand, workers are the "biggest losers to the regulation". I am interested in re-visiting this conclusion in a model where, consistently with the data, larger firms are more capital intensive. In this context, workers may suffer a milder cost because the 50 employees threshold redistributes market shares toward labor intensive firms.

${ }^{3}$ See Restuccia and Rogerson (2013) for a review of literature.
} 
My paper also adds to the literature which documents the dispersion in capital intensity across firms and studies its implications. Raval (2011) establishes the positive relationship between firm size and capital intensity in the US. Using a sufficient statistic approach, Oberfield and Raval (2014) show that the aggregate elasticity of substitution is increasing in the dispersion of capital shares across firms. By contrast, I show that the joint distribution of firm size and capital intensity shapes the distributional effects of productivity-based and size-based governement policies.

The rest of the paper is organised as follows. Section 2 describes the data and the motivating evidence. Section 2 sets out the general equilibrium model. In section 3, I present my calibration strategy and the results of my quantitative analysis of heterogeneous distortions. In Section 5 I analyse the sensitivity of my results to alternative modeling/calibration choices. Section 6 concludes.

\section{Data and Motivating Evidence}

The Data My empirical analysis relies on the balance sheet dataset BRN (for "Benefice Reels Normaux). The BRN database is constructed from mandatory reports of French firms to the tax administration and covers all firms subject to the normal tax regime, i.e. firms whose annual sales exceed a certain threshold or which choose the normal tax regime. ${ }^{4}$ The BRN contains between 650,000 and 750,000 firms per year over the period, which is around $60 \%$ of the total number of French firms. I exclude firms operating in agriculture, public administration and education from my sample (about 2,5\% of all firms). The dataset contains the main elements of firms' balance sheet. I essentially use two variables: the number of employees and the labor share of value added. I compute the labor share at the firm-level as the ratio of the wage bill (including payroll taxes) to value added. I exclude observations for which the wage bill, the value added or the number of employees are either negative or missing. I also exclude firms with less than 10 employees since the data has limited coverage for these firms. Table 1 provides summary statistics for the final sample.

Table 1: Summary Statistics

\begin{tabular}{lcccc}
\hline Variable & Obs & Mean & Median & Sd \\
\hline \# Employees & $2,022,534$ & 41.583 & 20 & 80.628 \\
Labor Share & $2,022,534$ & .817 & .807 & .267 \\
Wage Bill & $2,022,534$ & $1,296.885$ & 619 & 2287.637 \\
Value Added & $2,022,534$ & $1,804.625$ & 791.972 & $3,420.162$ \\
\hline
\end{tabular}

Notes : Wage bill and value added are expressed in $\mathrm{k} €$.

Motivating Evidence This paper makes the point that labor share differences across firms shape the aggregate consequences of resource misallocation. In this paragraph, I provide evidence that there are structural labor share differences across firms, and that these differences correlate to firm size. First, in table 2 I report the probability that a firm changes labor share deciles

\footnotetext{
${ }^{4}$ In 2007 , the thresholds were 763,000 euros in the trade or real estate sectors, and 230,000 euros otherwise.
} 
between two consecutive years. This transition probability matrix shows that a majority of firms stay in the same decile from year to year, suggesting that the individual labor share measured in the data captures structural differences across firms.

Table 2: Yearly Transition Matrix - Labor Share Decile

\begin{tabular}{|c|c|c|c|c|c|c|c|c|c|c|c|}
\hline \multirow[b]{2}{*}{ Decile $_{t}$} & \multicolumn{10}{|c|}{$\mathbf{P}\left(\right.$ Decile $_{t+1} \mid$ Decile $\left._{t}\right)$} & \multirow[b]{2}{*}{ Total } \\
\hline & 1 & 2 & 3 & 4 & 5 & 6 & 7 & 8 & 9 & 10 & \\
\hline 1 & 0.75 & 0.16 & 0.04 & 0.02 & 0.01 & 0.01 & 0.00 & 0.00 & 0.00 & 0.01 & 1.00 \\
\hline 2 & 0.16 & 0.47 & 0.20 & 0.07 & 0.03 & 0.02 & 0.01 & 0.01 & 0.01 & 0.01 & 1.00 \\
\hline 3 & 0.04 & 0.20 & 0.35 & 0.20 & 0.09 & 0.05 & 0.03 & 0.02 & 0.02 & 0.02 & 1.00 \\
\hline 4 & 0.01 & 0.07 & 0.19 & 0.29 & 0.19 & 0.10 & 0.06 & 0.03 & 0.03 & 0.03 & 1.00 \\
\hline 5 & 0.01 & 0.03 & 0.09 & 0.18 & 0.27 & 0.18 & 0.11 & 0.06 & 0.04 & 0.04 & 1.00 \\
\hline 6 & 0.01 & 0.02 & 0.05 & 0.10 & 0.17 & 0.26 & 0.18 & 0.11 & 0.07 & 0.05 & 1.00 \\
\hline 7 & 0.00 & 0.01 & 0.03 & 0.05 & 0.10 & 0.17 & 0.28 & 0.18 & 0.11 & 0.06 & 1.00 \\
\hline 8 & 0.00 & 0.01 & 0.02 & 0.03 & 0.06 & 0.10 & 0.18 & 0.32 & 0.19 & 0.09 & 1.00 \\
\hline 9 & 0.00 & 0.01 & 0.02 & 0.03 & 0.04 & 0.06 & 0.10 & 0.18 & 0.39 & 0.16 & 1.00 \\
\hline 10 & 0.01 & 0.02 & 0.02 & 0.03 & 0.04 & 0.05 & 0.06 & 0.08 & 0.15 & 0.56 & 1.00 \\
\hline
\end{tabular}

Second, in figure 2 I plot the mean log labor share per quantile of firm workforce size. Panel (a) is similar to introduction figure 1 except for the fact that firm-level log labor shares are de-meaned at the 2-digit industry-level. While the slope of the size-labor share relationship is about half smaller within industry than using pooled data, there are still substantial differences: the labor share of firms at the bottom of the distribution is almost $4 \%$ percentage points larger than at the top. In order to further control for differences across industries, in panel (b) I bin firms per (2-digit) industry-specific decile. This way, I ensure that a firm does not fall in the low percentiles while being large in its respective industry. Panel (b) looks very similar to panel (a), which further establishes the robustness of the labor share differences between small and large firms.

Panel (c) is similar to panel (b), except for the fact that it is constructed by percentile rather than decile. "Zooming in" to the percentile level of the size-labor share relationship reveals that beyond the negative trend, there is a dip right below the 80-th percentile. This region corresponds to the 50 employees threshold (represented by the vertical solid line). Garicano et al. (2016) provide a detailed list of additional rules which bind to French firms as they exceed 50 employees. They give evidence from the firm size distribution that some firms prefer to bunch at 50 employees rather then facing these additional constraints. Panel (c) of figure 2 documents a new margin of firm-level adjustment to the threshold: bunching firms appear to decrease their labor share as a way to expand their production of value added without exceeding the workforce threshold. One of my simulation exercises will investigate the labor share consequences of removing the 50 employees threshold. In the following section I present an extension of the neoclassical growth model from which I am able to replicate this pattern as well as the overall negative size-labor share relationship. 
Figure 2: Labor Share Versus Size across French Firms

(a) Within-Industry Labor Share Variation

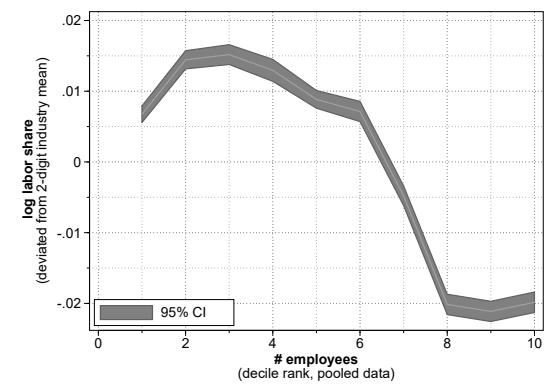

(b) Industry-Specific Size Deciles

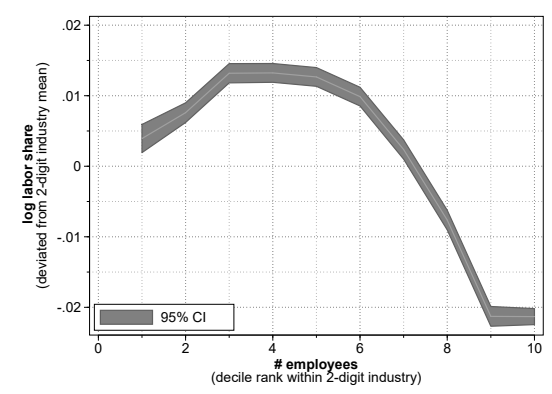

(c) "Zooming in" : Labor Share by Size Percentile

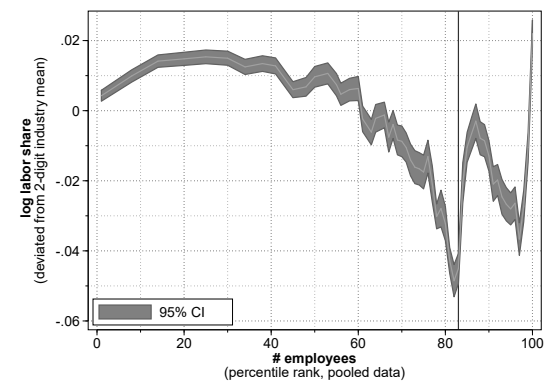

Notes: Each one of these three panels depicts the average log labor share by quantile of firm size. Firm-level $\log$ labor shares are de-meaned at the 2-digit industry level. Size quantiles are constructed from pooled data in panels (a) and (c), by 2-digit industry in (b).

\section{Model}

I consider a neoclassical growth model with firm level heterogeneity, as in Hopenhayn (1992) and Hopenhayn and Rogerson (1993). My model extends Restuccia and Rogerson (2008) in two ways. First, I introduce two-way heterogeneity across firms. More specifically, I assume that individual production functions differ not only in terms of total factor productivity but also in terms of factor elasticity. By allowing these two parameters to be correlated across firms, the model is able to replicate the cross-sectional relationship between size and labor share observed in the data. As a second extension, I model the 50 employees threshold in France: firms above 
50 employees face an (implicit) tax on labor. The rest of the model is similar to Restuccia and Rogerson (2008). Firms produce by combining capital and labor through a decreasing return to scale Cobb-Douglas technology. There is no firm-level dynamics: upon entry, firms draw a set of technological parameters that do not vary for the rest of their existence. All markets are competitive. I then use the model to study the impact of heterogeneous policy distortions on the aggregate labor share. I consider the case of the 50 employees threshold, as well as a class of generic policies distorting the relative price of output across firms. By reallocating resources across firms with heterogeneous factor intensity, these policy distortions modify the aggregate labor share.

\subsection{Base model}

The representative household owns national firms and is endowed with one unit of time at each period and $K_{0}>0$ units of capital stock at date 0 . At each period, the representative household allocates her different factor incomes into consumption and investment so as to maximise her intertemporal utility

$$
\sum_{t=0}^{\infty} \beta^{t} u\left(C_{t}\right),
$$

with $C_{t}$ the consumption at date $t, 0<\beta<1$ the discount factor and $u(\bullet)$ a well-behaved utility function.

Firms produce by combining capital and labor through a Cobb-Douglas production technology with decreasing returns to scale

$$
f(k, n, \varphi, \alpha)=\varphi\left(n^{\alpha} k^{1-\alpha}\right)^{\theta} .
$$

$n$ is the number of employees and $k$ the stock of capital. $\theta \in(0,1)$ is the degree of returns to scale. The narrative provided by Lucas (1978) for parameter $\theta$ being smaller than 1 is that managers have a limited "span-of-control", meaning that their ability to manage additional inputs is decreasing with the production scale. Assuming $\theta \geq 1$ would deliver the counterfactual feature that all capital and all individuals are employed by the single most productive firm in the economy. Finally, $\varphi$ and $\alpha$ are respectively the total factor productivity and the labor elasticity of a firm's production function.

To be able to stay on the market, incumbent firms must pay a per-period fixed cost of operation equal to $c_{f}$, measured in units of output. New firms can also be created at a cost $c_{e}$, also paid in output. After paying this cost, a realization of the firm-level parameters $\left(\varphi_{i}, \alpha_{i}\right)$ is drawn. I assume that there is a deterministic relationship between $\alpha_{i}$ and $\varphi_{i}: \alpha_{i}=\alpha\left(\varphi_{i}\right)$. $\varphi$ is drawn from a density $\mathcal{P}(\varphi)$.

Feasibility in this economy imposes

$$
C_{t}+X_{t}+c_{e} E_{t}+M_{t} c_{f} \leq Y_{t}
$$

where $C_{t}$ is aggregate consumption, $X_{t}$ is aggregate investment, $E_{t}$ is aggregate entry, $Y_{t}$ is aggregate output, and $M_{t}$ is the mass of producing firms. That is, total output should be large 
enough to cover consumption, investment and fixed production costs. The aggregate stock of capital evolves according to a standard law of motion

$$
K_{t+1}=(1-\delta) K_{t}+X_{t}
$$

with $\delta$ the depreciation rate.

\subsection{Policy distortions}

I consider two types of policy distortions. First, firms are subject to idiosyncratic tax rates $\tau_{i}^{(y)}$ and $\tau_{i}^{(k)}$ on output and capital, respectively. The elements of vector $\tau_{i} \equiv\left\{\tau_{i}^{(y)}, \tau_{i}^{(k)}\right\}$ can be positive, if firm $i$ is getting taxed, or negative if $i$ is getting subsidized. $\tau_{i}$ is drawn upon entry, along with technological parameter $\varphi_{i}$, from the joint density function $\mathcal{P}(\varphi, \tau)$. This density verifies

$$
\mathcal{P}(\varphi, \tau)=\mathcal{P}(\tau \mid \varphi) \times \mathcal{P}(\varphi)
$$

with $\mathcal{P}(\tau \mid \varphi)$ the density of $\tau$ conditional on $\varphi$. In my counterfactual analysis, I will consider different configurations for $\mathcal{P}(\tau \mid \varphi)$ (in particular, $\tau$ will be correlated or not to $\varphi$, depending on the simulation). The concept of "heterogeneous policy distortions" spans a broad set of policies, ranging from fiscal to trade policies. My modelling of the policy through idiosyncratic tax rates aims to be a general metaphor for this class of distortions.

Figure 3: Labor Costs

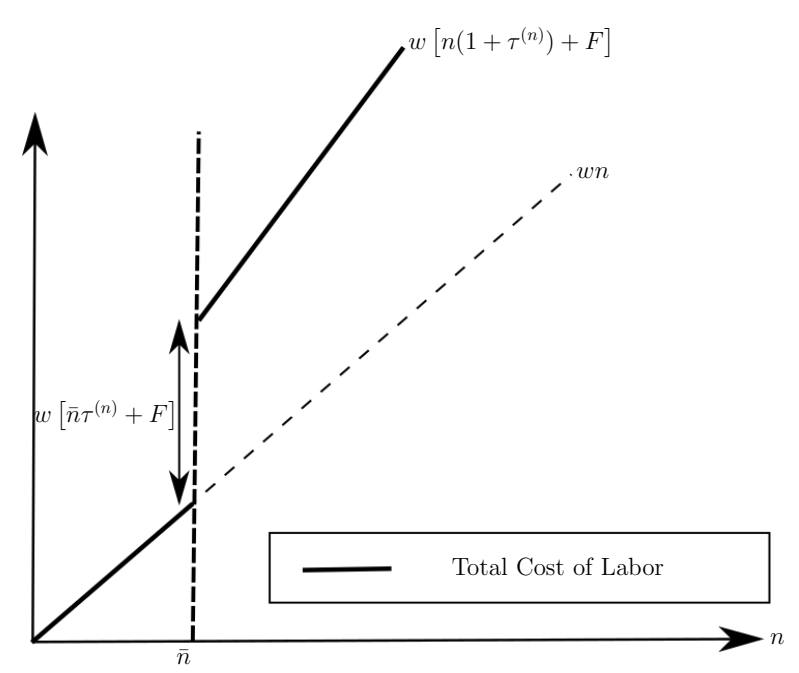

Notes: This figure depicts the theoretical relationship between total wage bill and workforce size $n$. The regulatory cut-off $\bar{n}$ creates a notch impacting both the fixed and marginal cost of labor. As a result, there is a positive discontinuity of magnitude $w\left(\bar{n} \tau^{(n)}+F\right)$ in the wage bill function at $\bar{n}$.

The second type of distortion is the 50 employees threshold, which I model as an implicit tax $\tau^{(n)}$ applying to firms with more than $\bar{n}$ workers. Following Garicano et al. (2016), I also include 
a fixed cost component $w F$ to the regulation triggering at $\bar{n}$. As one can see from the labor cost function sketched in figure 3, the average labor cost and the marginal labor cost both jump up at $\bar{n}$, although not in the same proportion. Average costs increase by $w\left(\tau^{(n)}+\frac{F}{\bar{n}}\right)$ while marginal costs increase by $w \tau^{(n)}$. Therefore, depending on whether $F$ is positive or negative, the regulation will have stronger effect on average costs or on marginal costs. Both the fixed and marginal costs associated to the regulatory threshold are paid in output. ${ }^{5}$

My motivation for studying the 50 employees threshold is twofold. First, as documented in figure 2 , the 50 employees threshold has large consequences on the relationship between size and labor share across firms in France. It is therefore necessary to model the threshold in order to be able to match this moment in the French data. Second, I am interested in revisiting the conclusions of existing papers on the 50 employees threshold. More specifically, Garicano et al. (2016) conclude that workers are the biggest losers because the 50 employees threshold lowers the demand for labor relative to capital within regulated firms. However, this conclusion may not hold once one take into account the fact that the threshold tends to substitute labor for capital across firms, by reallocating resources towards small, labor intensive firms.

The government's budget is balanced every period of time. This is achieved through a per-period lump-sum taxation $T$. If the distribution of firm-level distortions is such that total subsidies exceed total taxes, then $T$ will be negative, and vice versa if taxes exceed subsidies.

\subsection{Equilibrium}

\subsection{1 consumer problem}

The representative household maximises its lifetime utility subject to the intertemporal budget constraint

$$
\sum_{t=0}^{\infty} p_{t}\left(C_{t}+K_{t+1}-(1-\delta) K_{t}\right) \leq \sum_{t=0}^{\infty} p_{t}\left(r_{t} K_{t}+w_{t} N_{t}+\Pi_{t}-T_{t}\right),
$$

with $p_{t}, r_{t}, w_{t}$ respectively the output price, the rental price and the wage rate at date $t . N_{t}$ and $\Pi_{t}$ are respectively the aggregate labor supply and the aggregate after-tax profit. In words, budget constraint (2) means that permanent consumption plus investment must be lower or equal to permanent income, net of taxes. At the stationary equilibrium of this economy, Euler equation implies that

$$
r=\frac{1}{\beta}-(1-\delta)
$$

This means that the representative household will adjust its investment decisions to perfectly accommodate any shock on the aggregate demand for capital by national firms.

\footnotetext{
${ }^{5}$ I assume that the tax is paid in output (rather than labor), to make my results comparable to the literature. Garicano et al. (2016) assume that regulatory costs are paid in goods and conclude that the workers are the biggest losers to the regulation. By contrast, I claim that this result may not hold once labor share differences across small and large firms are considered. If I were to assume that the implicit tax was paid in labor, it would not be so clear whether I obtain a smaller effect on workers than Garicano et al. (2016) because I introduce labor share differences, or because firms need to hire workers to pay the tax, which partially offsets the detrimental effect of the regulation on labor demand.
} 


\subsection{2 incumbent firm's problem}

In each period, incumbent firms must decide whether on not to stay on the market and whether or not to exceed the regulatory threshold $\bar{n}$. Conditional on these two decisions, they must also determine their optimal demand for capital and labor.

Exit decision Let $\pi(\varphi, \tau)$ be the optimal per-period profit obtained by an incumbent firm with productivity $\varphi$ and a vector of output and capital tax rates $\tau=\left\{\tau^{(y)}, \tau^{(k)}\right\}$, Conditional on staying on the market, the profit of a firm is:

$\pi(\varphi, \tau)=\max _{n, k}\left\{\begin{array}{ll}\left(1-\tau^{(y)}\right) f(n, k ; \varphi, \alpha(\varphi))-\left(1+\tau^{(k)}\right) r k-w n-c_{f} & \text { if } n \leq \bar{n} \\ \left(1-\tau^{(y)}\right) f(n, k ; \varphi, \alpha(\varphi))-\left(1+\tau^{(k)}\right) r k-w n\left(1+\tau^{(n)}\right)-w F-c_{f} & \text { if } n>\bar{n}\end{array}\right.$.

If $\alpha$ was independent of productivity $\varphi$, profits would be strictly increasing with $\varphi$. However, because $\varphi$ also enters profits through labor elasticity $\alpha(\varphi)$, the sign of the relationship between profits and $\varphi$ is unclear. Suppose for instance that $\alpha$ drops very fast to zero with $\varphi$, and that capital is more expensive than labor. Then profits may decrease with $\varphi$ because high productivity firms are intensive in the most expensive production factor. I will therefore assume that the relationship between $\alpha$ and $\varphi$ is flat enough to guarantee that profits are stictly increasing with $\varphi$. This assumption will be verified when I calibrate the model. Moreover, I want to stress that I do not need this assumption to solve the model. It is only intended to facilitate its exposition.

Since there is no firm-level productivity dynamics, the present value of a firm, $W(\varphi, \tau)$, is simply equal to its per-period profit, discounted for the exogenous exit probability $\lambda$ and the real interest rate $R=r-\delta$ :

$$
W(\varphi, \tau)=\frac{\pi(\varphi, \tau)}{1-\rho}, \text { with } \rho \equiv \frac{1-\lambda}{1+R} .
$$

The present value of exiting is zero, so an incumbent firm exits the market if and only if its per-period profits, and therefore its present value, are negative. Since profits are strictly increasing with $\varphi$, for all $\tau$ there exists a unique productivity cutoff $\phi_{e}(\tau)$ (subscript "e" stands for "exit") such that an incumbent firm is indifferent to exit or remain on the market.

Regulatory regime There are three regulatory status. Firms can be "unconstrained" if they stay strictly below $\bar{n}$, "regulated" if they exceed $\bar{n}$, or bunching if their number of employees is exactly equal to $\bar{n}$. For unconstrained firms, the optimal labor and capital demands $n_{u}(\varphi, \tau)$ and $k_{u}(\varphi, \tau)$ are implicitly defined by first order conditions

$$
\left\{\begin{array}{l}
\left(1-\tau^{(y)}\right) \frac{\partial f}{\partial n}\left(n_{u}, k_{u} ; \varphi, \alpha(\varphi)\right)-w=0 \\
\left(1-\tau^{(y)}\right) \frac{\partial f}{\partial k}\left(n_{u}, k_{u} ; \varphi, \alpha(\varphi)\right)-\left(1+\tau^{(k)}\right) r=0
\end{array} .\right.
$$

If $\alpha$ was independent of productivity $\varphi, n_{u}\left(\varphi, \tau^{(y)}\right)$ would be strictly increasing with $\varphi$. However, just like for profits, the sign of the relationships becomes unclear as soon as $\varphi$ also enters the production function through labor elasticity $\alpha(\varphi)$. Therefore, I will assume that the relationship between $\alpha$ and $\varphi$ is flat enough to guarantee that labor demand $n_{u}\left(\varphi, \tau^{(y)}\right)$ is 
stictly increasing with $\varphi$. This assumption serves expositional purposes and will be verified in the calibrated model.

Since $n_{u}(\varphi, \tau)$ is strictly increasing with $\varphi$, for all $\tau$ there exists a productivity cutoff $\phi_{c}(\tau)$ (subscript "c" stands for "constrained") such that the optimal labor demand is exactly equal to the regulatory threshold. Formally this cutoff verifies

$$
n_{u}\left(\phi_{c}(\tau), \tau\right)=\bar{n} .
$$

Firms whose productivity exceeds $\phi_{c}(\tau)$ must trade-off between exceeding the threshold or bunching at $\bar{n}$. This amounts to choosing between being sub-optimally small or being regulated. Since the opportunity cost of not exceeding $\bar{n}$ is strictly increasing with $\varphi$, for all $\tau$ there exists a unique productivity cut-off $\phi_{r}(\tau)$ (subscript "r" stands for "regulated") making firms indifferent between bunching or being regulated. Specifically, for all $\tau$, this productivity cutoff solves the following indifference condition:

$$
\begin{aligned}
& \max _{k}\left(1-\tau^{(y)}\right) f\left(\bar{n}, k ; \phi_{r}, \alpha\left(\phi_{r}\right)\right)-w \bar{n}-\left(1+\tau^{(k)}\right) r k= \\
& \max _{n, k}\left(1-\tau^{(y)}\right) f\left(n, k ; \phi_{r}, \alpha\left(\phi_{r}\right)\right)-\left(1+\tau^{(n)}\right) w n-\left(1+\tau^{(k)}\right) r k-w F .
\end{aligned}
$$

Firms whose productivity lies between $\phi_{c}(\tau)$ and $\phi_{r}(\tau)$ are "bunching" firms. Their optimal capital demand $k_{b}(\varphi, \tau)$ is implicitly defined by first order condition

$$
\left(1-\tau^{(y)}\right) \frac{\partial f}{\partial k}\left(\bar{n}, k_{b} ; \varphi, \alpha(\varphi)\right)-\left(1+\tau^{(k)}\right) r=0 .
$$

For regulated firms $\left(\varphi>\phi_{r}(\tau)\right)$, the optimal labor and capital demand $n_{r}(\varphi, \tau)$ and $k_{r}(\varphi, \tau)$ are implicitly defined by first order conditions

$$
\left\{\begin{array}{l}
\left(1-\tau^{(y)}\right) \frac{\partial f}{\partial n}\left(n_{r}, k_{r} ; \varphi, \alpha(\varphi)\right)-\left(1+\tau^{(n)}\right) w=0 \\
\left(1-\tau^{(y)}\right) \frac{\partial f}{\partial k}\left(n_{r}, k_{r} ; \varphi, \alpha(\varphi)\right)-\left(1+\tau^{(k)}\right) r=0 .
\end{array}\right.
$$

In summary, the optimal labor and capital demand verify

$$
\begin{aligned}
n^{*}(\varphi, \tau) & = \begin{cases}0 & \text { if } \varphi<\phi_{e}(\tau) \\
n_{u}(\varphi, \tau) & \text { if } \phi_{e}(\tau) \leq \varphi<\phi_{c}(\tau) \\
\bar{n} & \text { if } \phi_{c}(\tau) \leq \varphi<\phi_{r}(\tau) \\
n_{r}(\varphi, \tau) & \text { if } \phi_{r}(\tau)<\varphi\end{cases} \\
k^{*}(\varphi, \tau) & = \begin{cases}0 & \text { if } \varphi<\phi_{e}(\tau) \\
k_{u}(\varphi, \tau) & \text { if } \phi_{e}(\tau) \leq \varphi<\phi_{c}(\tau) \\
k_{b}(\varphi, \tau) & \text { if } \phi_{c}(\tau) \leq \varphi<\phi_{r}(\tau) \\
k_{r}(\varphi, \tau) & \text { if } \phi_{r}(\tau)<\varphi,\end{cases}
\end{aligned}
$$

and the labor share at the individual level is equal to

$$
l s(\varphi, \tau)=\frac{w n^{*}(\varphi, \tau)}{\pi(\varphi, \tau)+w n^{*}(\varphi, \tau)+r k^{*}(\varphi, \tau)} .
$$


In figure 4, 5 and 6, I respectively sketch the optimal number of employees $n^{*}$, the optimal capital-labor ratio $\frac{k^{*}}{n^{*}}$, and the labor share as a function of $\varphi$, keeping $\tau$ constant. Let us consider the optimal number of employees first (figure 4). For low productivity firms, the optimal size is strictly increasing with $\varphi$. Between $\phi_{c}(\tau)$ and $\phi_{r}(\tau)$, firms are bunching at $\bar{n}$. As $\varphi$ gets large enough to justify being regulated, firms do not pick a size just above $\bar{n}$ but rather "jump" far from the threshold. This is because exceeding the threshold imposes a fixed cost $w\left(\bar{n} \tau^{(n)}+F\right)$ to firms. Firms need to be large enough to make it worth paying this fixed cost. Finally, for $\varphi$ larger than $\phi_{r}(\tau)$, firm size is strictly increasing with $\varphi$. Note, however, that because the regulation increases the marginal cost of labor, firms above $\bar{n}$ are smaller than what they would be in the absence of the regulation, keeping factor prices fixed.

When it comes to the capital-labor ratio (figure 5), it is increasing with $\varphi$ among lowproductivity firms. This is simply because I drew figure 5 assuming that $\alpha(\varphi)$ is decreasing with $\varphi$, so that high productivity firms are more capital-intensive (consistently with the data). Among bunching firms, the capital-labor ratio is higher than it would be without regulation: firms mitigate part of the opportunity cost of bunching at $\bar{n}$ by investing in capital, the more so the higher the productivity. Among regulated firms, the capital-labor ratio is also higher than what it would be without regulation due to the implicit tax on labor, $\tau^{(n)}$, leading firms to substitute capital for labor.

The relationship between labor share and $\varphi$ mirrors the one between capital-labor ratio and $\varphi$ : assuming again that $\alpha$ depends negatively on $\varphi$, labor share will be decreasing with $\varphi$ as plotted in figure 6. The fact that bunching firms increase their capital-labor ratio translates into lower labor shares at the threshold, consistently with the data. Moreover, regulated firms have a smaller labor share than in the absence of the regulation because they substitute capital for labor.

Figure 4: TFP-Size Relationship

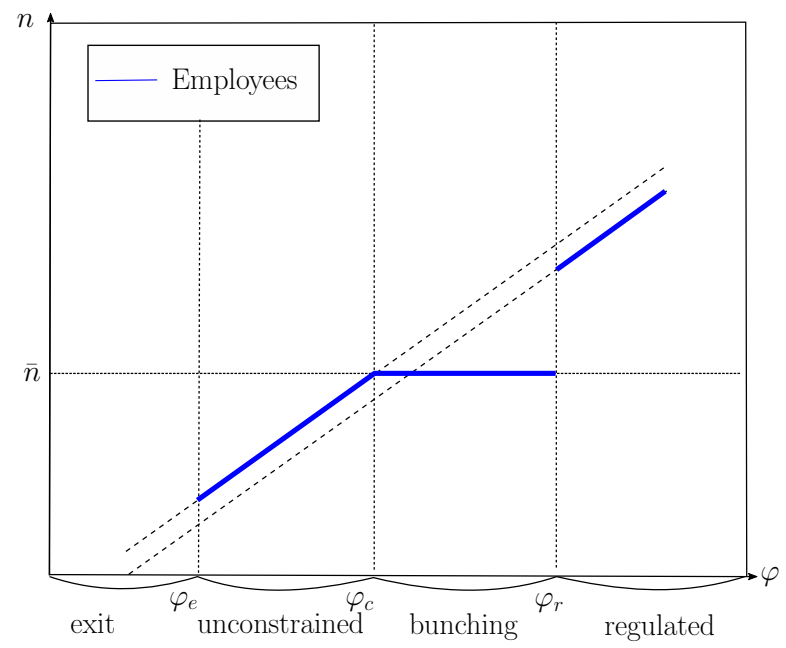

Notes: This figure depicts the relationship between produtivity $\varphi$ and optimal workforce size $n$, keeping idiosyncratic tax rates $\tau$ fixed. 
Figure 5: TFP versus Capital-labor Ratio

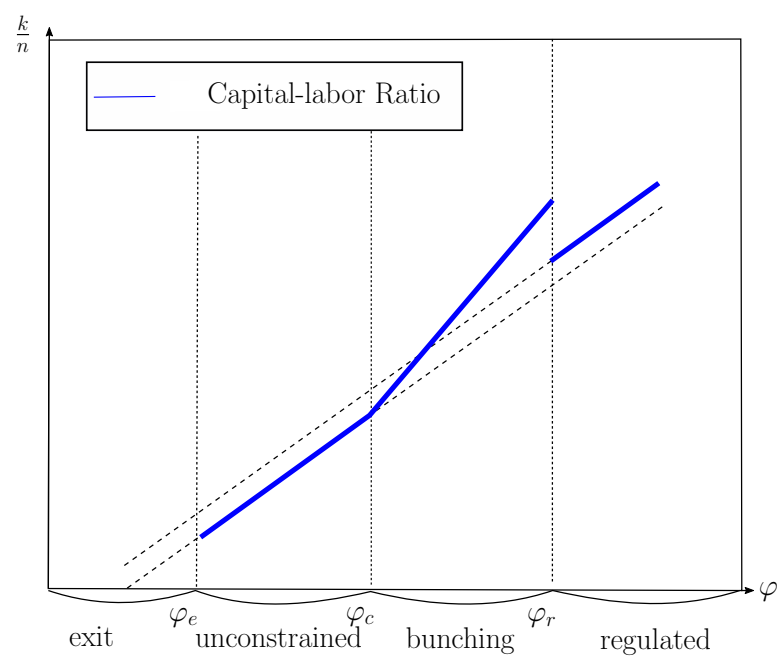

Notes: This figure depicts the relationship between productivity $\varphi$ and the capital-to-labor ratio, keeping idiosyncratic tax rates $\tau$ fixed. Consistently with the data, the figure assumes that labor intensity $\alpha(\varphi)$ is an increasing function of $\varphi$.

Figure 6: TFP versus Labor Share

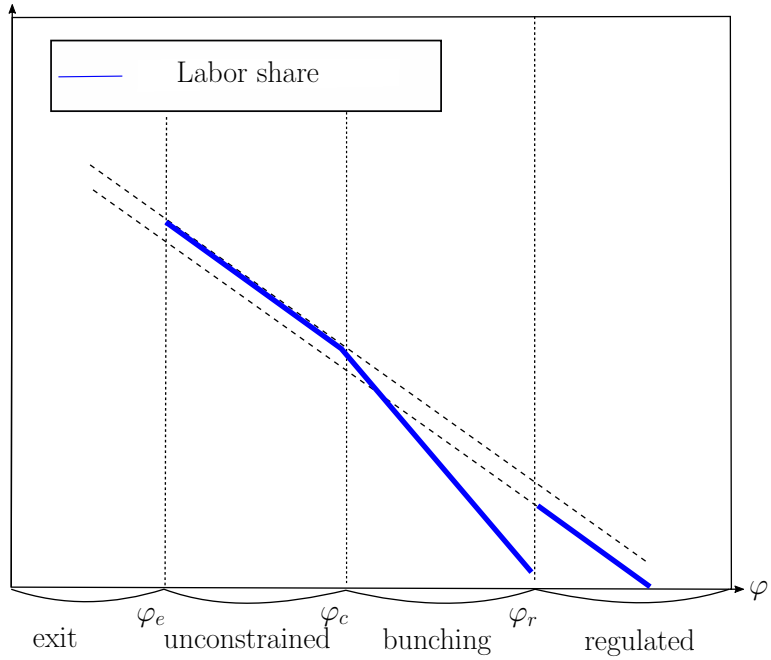

Notes: This figure depicts the relationship between productivity $\varphi$ and the optimal labor share of value added, keeping idiosyncratic tax rates $\tau$ fixed. Consistently with the data, the figure assumes that labor intensity $\alpha(\varphi)$ is an increasing function of $\varphi$.

\subsubsection{Entering establishment's problem}

Let $W_{e}$ be the expected present value of entry, net of the entry cost:

$$
W_{e}=\int\left\{x(\varphi, \tau) W(\varphi, \tau)-c_{e}\right\} g(\varphi, \tau) d \varphi d \tau
$$


with $x(\varphi, \tau)$ a dummy variable equal to one if the firm decides to not exit (i.e. if $\varphi \geq \phi_{e}(\tau)$ ). Firms are willing to enter as long as $W_{e}$ is positive. Since $W_{e}$ is decreasing with $w$, one can solve for the stationary equilibrium wage of the economy by equalizing $W_{e}$ to zero.

\subsubsection{Invariant Distribution of Firms}

Let $\mu(\varphi, \tau)$ and $\mu^{\prime}(\varphi, \tau)$ be respectively the current and next period mass of firms at point $(\varphi, \tau)$. The law of motion on firm distribution is

$$
\mu^{\prime}(\varphi, \tau)=(1-\lambda) \mu(\varphi, \tau)+x(\varphi, \tau) g(\varphi, \tau) E .
$$

In words, the mass of firms at the next period is equal to the current mass of firms, minus the mass of firms hit by an exogenous exit shock, plus the mass of entering firms deciding to survive on the market.

At the stationary equilibrium of the economy, $\mu^{\prime}(\varphi, \tau)=\mu(\varphi, \tau)$, which implies

$$
\mu(\varphi, \tau)=E \frac{x(\varphi, \tau)}{\lambda} g(\varphi, \tau)
$$

\subsubsection{Definition of the Equilibrium}

A steady-state competitive equilibrium of this economy is a wage rate $w$, a rental rate $r$, a lump-sum tax $T$, a distribution $\mu(\varphi, \tau)$, a mass of entry $E$, value functions $W(\varphi, \tau), \pi(\varphi, \tau)$, $W_{e}$, policy functions $k^{*}(\varphi, \tau), n^{*}(\varphi, \tau), x(\varphi, \tau)$, aggregate consumption $(C)$ and capital $(K)$ such that:

1. the intertemporal utility of the household is maximized (equation 3 )

2. functions $\pi, W, W_{e}, k^{*}, n^{*}$ and $x$ solve the problem of entering and incumbent firms

3. the wage rate $w$ solves the free-entry condition $W_{e}=0$

4. $E$ and $K$ clear the labor market and the capital market:

$$
\begin{aligned}
N(=1) & =\int n^{*}(\varphi, \tau) \mu(\varphi, \tau) d \varphi d \tau \\
K & =\int k^{*}(\varphi, \tau) \mu(\varphi, \tau) d \varphi d \tau
\end{aligned}
$$

5. the output market clears:

$$
C+\delta K=G D P .
$$

The right-hand side of (6) corresponds to the aggregate value added of the economy, that is the total output, net of fixed operating costs and sunk entry costs:

$$
G D P \equiv \int\left(y(\varphi, \tau)-c_{f}\right) \mu(\varphi, \tau) d \varphi d \tau-c_{e} E
$$

The left hand-side of (6) is the sum of aggregate consumption and investment. 
6. The governement budget is balanced:

$$
T+\int\left\{\tau^{(y)} y(\varphi, \tau)+\tau^{(k)} r k^{*}(\varphi, \tau)+\left(\varphi \geq \phi_{r}(\tau)\right) w\left[\tau^{(n)} n^{*}(\varphi, \tau)+F\right]\right\} \mu(\varphi, \tau) d \varphi d \tau=0
$$

7. There is an invariant distribution of firms (equation 5).

\subsubsection{The Aggregate Labor Share: Definition and Insights}

The labor share of national income $L S$ is equal to the ratio of the aggregate labor income over national value added:

$$
L S \equiv \frac{w N+T_{N}}{G D P}=\frac{w N+T_{n}}{w N+r K+\Pi+T},
$$

with $T_{N}$ the lump-sum tax levied on workers (respectively $T-T_{N}$ is the lump-sum tax levied on capital income) and $\Pi$ the aggregate profit (net of operating and entry costs). The second equality in (7) simply results from the national accounting identity GDP = total factor remuneration. I assume that the lump-sum transfer is neutral, in the sense that the labor share pre lump-sum transfer and post lump-sum transfer are equal. Therefore, I can re-write $L S$ as follows:

$$
L S=\frac{w N}{w N+r K+\Pi} .
$$

Now suppose that the economy is in a distortion-free equilibrium and the governement decides to start taxing a subset $\mathcal{T}$ of firms. To build an intuition as to the consequences of such an hetereogeneous policy distortion, it is useful to re-write the aggregate labor share as a weighted mean:

$$
L S=L S^{\mathcal{T}} \omega^{\mathcal{T}}+L S^{-\mathcal{T}}\left(1-\omega^{\mathcal{T}}\right)
$$

With $L S^{\mathcal{T}}$ and $L S^{-\mathcal{T}}$ the average labor share among firms targeted and not-targeted by the tax, respectively. $\omega^{\mathcal{T}}$ is the share of $\mathcal{T}$ firms in national GDP. Then the partial effect of the intervention ("partial" in the sense that factor prices are kept constant) on the national labor share is:

$$
\frac{\partial L S}{\partial \tau}=\underbrace{\frac{\partial L S^{\mathcal{T}}}{\partial \tau} \omega^{\mathcal{T}}}_{\text {Within-firm }}+\underbrace{\left(L S^{\mathcal{T}}-L S^{-\mathcal{T}}\right) \frac{\partial \omega^{\mathcal{T}}}{\partial \tau}}_{\text {Between-firm }} .
$$

Although 8 only describes the partial effect of distortions, it will provide useful insights throughout my simulation results. Expression 8 tells us that the partial effect of heterogeneous policy distortions will always have a two components. The first component is a within (taxed)firm effect: taxed firms adjust their labor share to the tax. This effect is all the more important as taxed firms have a large market share $\omega^{\mathcal{T}}$. The second component is a between firm effect: the 
tax reduces the weight of taxed firm in the overall labor share. This effect is large if indivdual market shares are very elastic to the tax and if labor share differences between taxed and untaxed firms is large. The main contribution of this paper is to show that this between-firm effect can be large.

\section{Quantitative analysis}

\subsection{Calibration}

In order to bring the model to the data, I need to make parametric assumptions regarding the joint distribution of $\varphi$ and $\alpha$. First, I assume that $\alpha$ is a logistic function of $\varphi$ :

$$
\alpha(\varphi)=\frac{\exp (a+b \ln (\varphi))}{1+\exp (a+b \ln (\varphi))} \in[0,1] .
$$

This logistic relationship guarantees that $\alpha$ lies on the $[0,1]$ interval. Parameter $b$ in equation (9) plays a central role in my analysis. It governs the slope of the relationship between firm size and labor share. If $b=0$, labor share is identical between small and large firms and the labor share impact of heterogeneous policy distortions is no different from the one of homogeneous policy distortions.

My second parametric assumption regards the distribution of $\varphi$. I assume that $\varphi$ follows a truncated pareto distribution with slope $\kappa$, lower bound $\underline{\varphi}$ and upper bound $\bar{\varphi}^{6}$ :

$$
P(\varphi<x)=\frac{1-(\underline{\varphi} / x)^{\kappa}}{1-(\underline{\varphi} / \bar{\varphi})^{\kappa}} .
$$

The different parameters of the model are calibrated either by targeting moments of the data, or by obtaining values from the literature. Table 3 lists the different parameter values, along with their source/target. $\delta$, the depreciation rate, is calibrated so that the share of investment in GDP equals 21\%, as observed in France over the period 2000-2007. ${ }^{7} \beta$, the discount rate, is set to match a $4 \%$ annual real interest rate. $\lambda$, the exogeneous exit probability, is set equal to 13\%, the exit rate observed in France over the period (Aghion et al., 2018).

The degree of returns to scale $\theta$ is calibrated from Garicano et al. (2016). Their estimate of $\theta$ is 0.86 . It is obtained through production function estimation using firm-level data for France over the same period as in this paper (1995-2007). $\theta$ is an important parameter because it governs the elasticity of firm size to idiosyncratic taxation: the larger $\theta$, the more individual firm size responds to price distortions, the more misallocation is induced by a given dispersion of idiosyncratic tax rates. In the sensitivity analysis section (section 5), I therefore report counterfactual results obtained with alternative values of $\theta$.

$a$ is calibrated to match the average log labor share my sample. I calibrate $b$ to match the average difference in the log labor share above and below median firm size; log labor shares are centered by 2 -digit industry and medians are computed by 2 -digit industry. $\underline{\varphi}$ and $\bar{\varphi}$, are

\footnotetext{
${ }^{6}$ Note that because productivity $\varphi$ enters the production function both directly and indirectly through $\alpha$ (equation 9), firm size is not a power function of $\varphi$ in my model (except if $b=0$ ). As a result, firm size distribution will not be pareto in general, even if the productivity distribution is. Nevertheless, I show in my calibration results that I get a firm size distribution very close to being Pareto, which allows me to fit the empirical distribution well.

7 https://ec.europa.eu/eurostat/fr/web/products-datasets/product?code=sdg_08_11
} 
obtained by targeting a minimum firm size of 10 workers and a maximum firm size of 10,000 workers. $\kappa$ is obtained by targeting the median firm size in my sample (21 workers). The entry cost $c_{e}$ is normalized to $1 . c_{f}$, the fixed cost of production, is fixed to zero in our main simulations. In section 5 , I investigate the role of selection by considering strictly positive values for $c_{f}$.

Finally, I calibrate $\tau^{(n)}$, the variable cost of the 50 employees threshold, from Garicano et al. (2016). By contrast, I set $F$, the fixed cost of the threshold, equal to zero. ${ }^{8}$

Beside the 50 employees threshold, the other idiosyncratic distortions are assumed absent from the factual world (i.e. $\tau^{(y)}$ and $\tau^{(k)}$ are equal to zero for all firms). In order to assess the ability of my calibrated model to fit the data, I simulated a sample with 2,022,534 observations (as in the actual sample), and plotted in 7 and 8 the firm size distribution and the size-labor share relationship in the actual and in the simulated data. ${ }^{9} \mathrm{My}$ model does a good job at fitting the labor share, including in the neighborhood of the 50 threshold. When it comes to firm size distribution, my model matches well the distribution away from 50, and in particular the fact that the whole distribution above 50 is shifted to the left due to the variable $\operatorname{cost} \tau^{(n)}$. However, as discussed in previous pragraph, my model predicts a deficit of firms right above 50 which is not in the data. As emphasized by Gourio and Roys (2014), this could be due to the fact that the regulation imposes more of a sunk cost than a per period fixed cost to firms. In any case, my sensitivity analysis presented in appendix $B$ suggests that my ability to fit this moment is not crucial for the results of my policy experiments.

\subsection{Simulation Results}

In this section, I consider the consequences on the aggregate labor share of imposing heterogeneous taxes/subsidies across firms. I consider three different types of tax: on output, on capital and on labor.

\subsubsection{Output Price Distortions}

I start off by considering the case of output price distortion. I simulate the effect of imposing an output tax rate $\tau$ on $50 \%$ of firms and an ouput subsidy $\tau_{s}$ on the other half. To compute the effects I take as a reference point the distortion-free equilibrium (i.e. $\tau_{i}^{(y)}=0$ for all $i$ and $\left.\tau^{n}=F=0\right) .{ }^{10}$

I first assume that the distribution of idiosyncratic distortions is uncorrelated to $\varphi$ : for any productivity level, 50\% of firms get taxed and 50\% get subsidized. Following Restuccia and Rogerson (2008), I calibrate $\tau_{s}$ to guarantee that the aggregate stock of capital, $K$, is unaffected by the policy. This way, I am able the isolate the effect of distortions through resource misallocation from effects through changes in aggregate resources.

\footnotetext{
${ }^{8}$ Using F's value from Garicano et al. (2016) instead, I get a better fit around the threshold for the firm size distribution but a poorer fit for the size-labor share relationship. Since the latter relationship is central to my paper, I prefer $F=0$. In appendix B I report the fit using $F$ estimate from Garicano et al. (2016). One can observe that the quality of fit away from 50 is comparable to the one I get fixing $F=0$ (see figures 7 and 8 ). In appendix B I also report my policy experiment results obtained calibrating $F$ from Garicano et al. $(2016)$. They are comparable to the ones obtained with $F=0$, as reported in section 4.2

${ }^{9}$ To simulate the data, I assumed a $12 \%$ measurement error on firm size, as estimated in Garicano et al. (2016).

${ }^{10}$ This equilibrium is obtained by removing the 50 employees threshold (i.e. by switching regulatory costs $\tau^{\bar{n}}$ and $F$ to zero). I describe the simulated effects of this removal in subsection 4.2 .3 and in table 10
} 
Table 3: Calibration of Model Parameters

\begin{tabular}{lcc}
\hline parameter & value & target/source \\
\hline$\delta$ & 0.08 & $\frac{X}{G D P}=21 \%$ \\
$\beta$ & 0.96 & $R=4 \%$ \\
$\lambda$ & $13 \%$ & annual exit rate \\
$\theta$ & 0.86 & Garicano et al. $(2016)$ \\
$c_{f}$ & 0 & fixed \\
$c_{e}$ & 1 & ln labor share (mean) \\
$a$ & 1.10 & $n(\bar{\varphi})=10$ \\
$b$ & -0.23 & ln labor share (above - below median) \\
$\varphi$ & 0.053 & Median firm size \\
$\overline{\bar{\varphi}}$ & 0.166 & Garicano et al. $(2016)$ \\
$\kappa$ & 6.14 & fixed \\
$\tau^{(n)}$ & 0.023 & 0 \\
$F$ & 0 & \multicolumn{2}{c}{. }
\end{tabular}

Notes : This table lists the targets (or sources) used in the calibration of the model, along with the value obtained for the corresponding parameter. Parameter $b$ is calibrated to match the above median/below median difference in the mean log labor share within 2-digit industries (i.e., log labor shares are demeaned by industry and the median size is industry-specific).

The results from this exercise are reported in table 4 for different levels of tax rate. I obtain values of $\tau_{s}$ consistently smaller that $\tau$. This is because firm-level capital demand is convex in the net price of output, $\left(1-\tau^{(y)}\right)$. In other words, the capital stock increases more with $\tau_{s}$ than it decreases with $\tau$. Therefore, subdsidized firms need little subsidy to absorb the capital of taxed firms and preserve the aggregate stock of capital. The reallocation induced by the policy implies that taxed firms are sub-optimally small and subsidized firm suboptimally large, which results in a sizable loss of GDP (from $2 \%$ for $\tau=10 \%$, to $10 \%$ for $\tau=50 \%$ ).

As for the national labor share, is it not affected by uncorrelated policy distortions. Intuitively, this is because the policy triggers a re-distribution of resources across firms with identical labor shares on average. In terms of equation 8, this means that the between-firm effect is nil, because $L S^{\mathcal{T}}-L S^{-\mathcal{T}}=0$. The within-firm effect is also zero because the distortion does not impact the firm-level labor share: since the production function is Cobb-Douglas, the firm-level labor to capital expenditure ratio is $\frac{w n_{i}}{r k_{i}}=\left(1+\tau_{i}^{(k)}\right)^{-1} \frac{\alpha_{i}}{1-\alpha_{i}}$. This ratio does not depend on $\tau_{i}^{(y)}$, neither directly nor indirectly, through $w$ and $r$.

To see what happens when idiosyncratic distortions are correlated to productivity, I now consider a policy which taxes the $50 \%$ most productive firms and subsidizes the $50 \%$ least productive. The results are reported in panel A of table 5. The subsidy rate $\tau_{s}$ required to maintain the aggregate stock of capital constant is larger than the tax rate tau. This is because subsidized firms are small, therefore they need a large incentive to expand enough and absorb the capital of shrinking taxed firms. As a consequence, subsidized firms are further away from their optimal size than they are in the case of uncorrelated distortions, which results in a larger a loss of GDP (up to 31\%). This result that correlated distortions are more detrimental to GDP is broadly consistent with the misallocation literature. 
Figure 7: Firm Size Distribution - Data versus Simulation

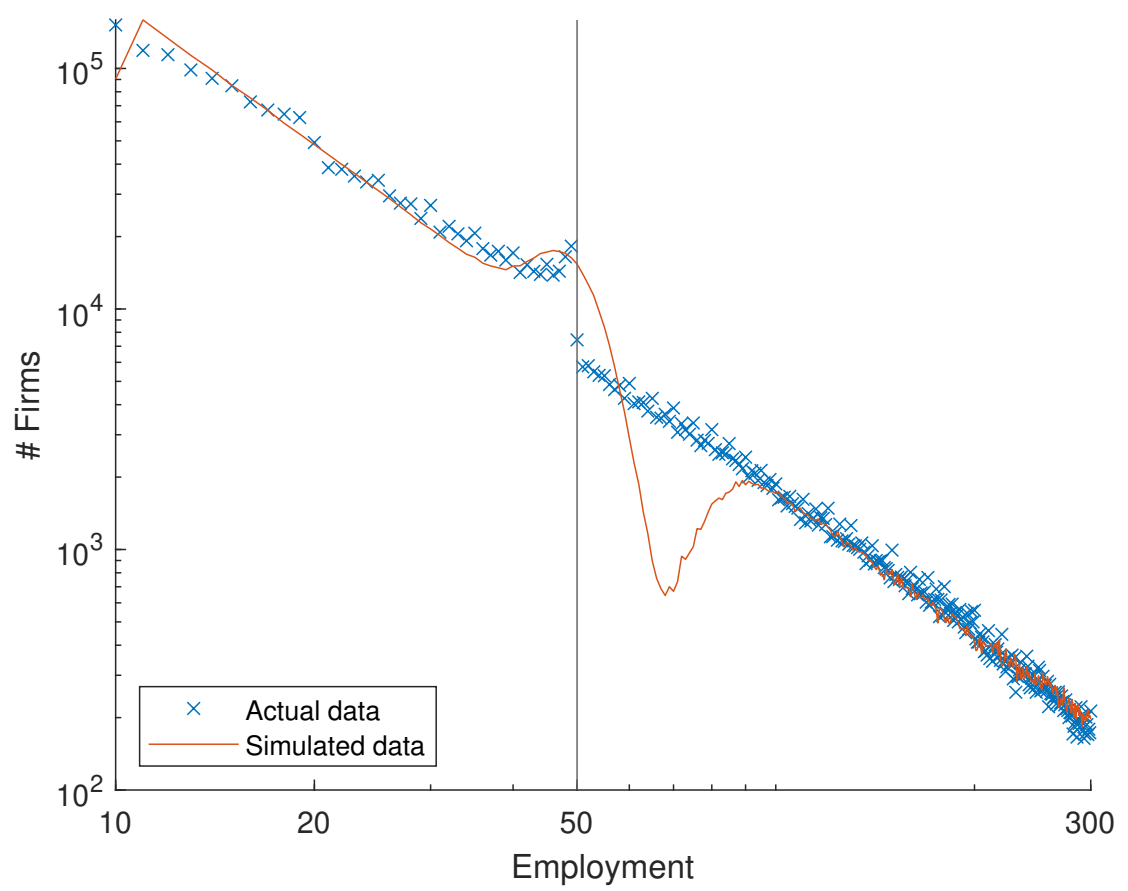

Notes: This figure depicts the firm size density, both in the data and in a sample simulated from the model. The simulated sample has the same size as the actual sample and is obtained using parameter values reported in table 3

By contrast, the main novelty of table 5 is to show that correlated distortions can also have a sizable effect on the labor share. For instance, a $50 \%$ tax on output generates a 2 percentage points increase in the labor share. To put this number in perspective, in table 6 I report the labor share for the G20 countries obtained from the OECD National Accounts Database. 2 percentage points represents a third of the labor share standard deviation across G20. One can also look at the results from table 5 through the lens of differences between France and the US. While these two countries roughly had the same labor share at the beginning of my sample (1995), US labor share has dropped about 5 points below French one towards the end of my sample (2005). The effects that I obtain represent $40 \%$ of the labor share difference than opened up during the period between France and the US. Finally, 2 percentage points also stands for $40 \%$ of the 5 percentage points decrease estimated by Karabarbounis and Neiman (2014) at the global level since the early 80's. To sum up, table 5 shows that the effects of correlated distortions on the labor share can be sizable in comparison to labor share variations observed across countries and over time.

The way correlated distortions impact the labor share is through a composition effect: taxation on large firms increases the weight of high-labor share firms in the economy, which increases the aggregate labor share. In other words, absent $\alpha$ differences across firms, the labor share would be unaffected by the policy. To highlight the role of labor share heterogeneity in my results, I re-run the same correlated policy simulations under an alternative model calibration with identical $\alpha$ 's across firms. That is, instead of calibrating $b$ by matching the labor share 
Table 4: Uncorrelated Output Distortions

\begin{tabular}{lrrrrr}
\hline tax rate $(\boldsymbol{\tau})$ & $\mathbf{1 0 . 0 0} \mathbf{\%}$ & $\mathbf{2 0 . 0 0} \mathbf{\%}$ & $\mathbf{3 0 . 0 0} \mathbf{\%}$ & $\mathbf{4 0 . 0 0} \%$ & $\mathbf{5 0 . 0 0} \mathbf{\%}$ \\
\hline subsidy rate $\left(\tau_{s}\right)$ & $6.12 \%$ & $8.55 \%$ & $9.58 \%$ & $9.99 \%$ & $10.14 \%$ \\
$\Delta$ GDP & $-2.02 \%$ & $-5.10 \%$ & $-7.55 \%$ & $-9.10 \%$ & $-9.91 \%$ \\
$\Delta$ Labor share & $0.00 \%$ & $0.00 \%$ & $0.00 \%$ & $0.00 \%$ & $0.00 \%$ \\
& $(0.00$ p.p. $)$ & $(0.00$ p.p. $)$ & $(0.00$ p.p. $)$ & $(0.00$ p.p. $)$ & $(0.00$ p.p. $)$ \\
$\Delta$ mean firm size & $0.00 \%$ & $0.00 \%$ & $0.00 \%$ & $0.00 \%$ & $0.00 \%$ \\
$\Delta E$ & $0.00 \%$ & $0.00 \%$ & $0.00 \%$ & $0.00 \%$ & $0.00 \%$ \\
$\Delta K$ & $0.00 \%$ & $0.00 \%$ & $0.00 \%$ & $0.00 \%$ & $0.00 \%$ \\
$\Delta w$ & $0.00 \%$ & $0.00 \%$ & $0.00 \%$ & $0.00 \%$ & $0.00 \%$ \\
$\Delta r$ & $0.00 \%$ & $0.00 \%$ & $0.00 \%$ & $0.00 \%$ & $0.00 \%$ \\
\hline
\end{tabular}

Notes: This table reports the effect of imposing a tax rate $\tau$ on the output of $50 \%$ of the firms. The steady-state capital stock is kept constant through a subsidy $\tau_{s}$ on the output of non-taxed firms. Taxed firms are selected randomly, independently of their productivity.

Table 5: Correlated Output Distortions

\begin{tabular}{|c|c|c|c|c|c|}
\hline tax rate $(\tau)$ & $10.00 \%$ & $20.00 \%$ & $30.00 \%$ & $40.00 \%$ & $50.00 \%$ \\
\hline \multicolumn{6}{|c|}{ Panel A: Baseline Calibration } \\
\hline subsidy rate $\left(\tau_{s}\right)$ & $38.14 \%$ & $45.11 \%$ & $47.71 \%$ & $48.71 \%$ & $49.06 \%$ \\
\hline$\Delta \mathrm{GDP}$ & $-13.08 \%$ & $-22.14 \%$ & $-27.25 \%$ & $-29.94 \%$ & $-31.20 \%$ \\
\hline \multirow[t]{2}{*}{$\Delta$ Labor share } & $1.85 \%$ & $2.45 \%$ & $2.69 \%$ & $2.79 \%$ & $2.82 \%$ \\
\hline & (1.30 p.p.) & (1.73 p.p.) & (1.90 p.p.) & (1.96 p.p.) & (1.99 p.p.) \\
\hline$\Delta$ mean firm size & $-4.96 \%$ & $-6.57 \%$ & $-7.21 \%$ & $-7.47 \%$ & $-7.56 \%$ \\
\hline$\Delta E$ & $5.22 \%$ & $7.03 \%$ & $7.77 \%$ & $8.07 \%$ & $8.18 \%$ \\
\hline$\Delta K$ & $0.00 \%$ & $0.00 \%$ & $0.00 \%$ & $0.00 \%$ & $0.00 \%$ \\
\hline$\Delta w$ & $7.16 \%$ & $9.65 \%$ & $10.68 \%$ & $11.08 \%$ & $11.23 \%$ \\
\hline$\Delta r$ & $0.00 \%$ & $0.00 \%$ & $0.00 \%$ & $0.00 \%$ & $0.00 \%$ \\
\hline \multicolumn{6}{|c|}{ Panel B: $\operatorname{corr}(\varphi, \alpha)=0$} \\
\hline subsidy rate $\left(\tau_{s}\right)$ & $28.29 \%$ & $34.77 \%$ & $37.23 \%$ & $38.18 \%$ & $38.52 \%$ \\
\hline$\Delta \mathrm{GDP}$ & $-8.93 \%$ & $-18.52 \%$ & $-24.94 \%$ & $-28.57 \%$ & $-30.34 \%$ \\
\hline \multirow[t]{2}{*}{$\Delta$ Labor share } & $0.00 \%$ & $0.00 \%$ & $0.00 \%$ & $0.00 \%$ & $0.00 \%$ \\
\hline & (0.00 p.p.) & (0.00 p.p.) & (0.00 p.p.) & (0.00 p.p.) & (0.00 p.p.) \\
\hline$\Delta$ mean firm size & $0.00 \%$ & $0.00 \%$ & $0.00 \%$ & $0.00 \%$ & $0.00 \%$ \\
\hline$\Delta E$ & $0.00 \%$ & $0.00 \%$ & $0.00 \%$ & $0.00 \%$ & $0.00 \%$ \\
\hline$\Delta K$ & $0.00 \%$ & $0.00 \%$ & $0.00 \%$ & $0.00 \%$ & $0.00 \%$ \\
\hline$\Delta w$ & $0.00 \%$ & $0.00 \%$ & $0.00 \%$ & $0.00 \%$ & $0.00 \%$ \\
\hline$\Delta r$ & $0.00 \%$ & $0.00 \%$ & $0.00 \%$ & $0.00 \%$ & $0.00 \%$ \\
\hline
\end{tabular}

Notes: This table reports the effect of imposing a tax rate $\tau$ on the output of the $50 \%$ most productive firms. The steady-state capital stock is kept constant through a subsidy $\tau_{s}$ on the output of the least productive firms. In panel A, I use benchmark calibration from table 3 In panel B, the model is calibrated as described in table 14 i.e. imposing symmetric labor elasticity $\alpha$ across firms. 
Table 6: Labor Share in the G20

\begin{tabular}{lrrrr}
\hline & $\mathbf{1 9 9 5}$ & $\mathbf{2 0 0 0}$ & $\mathbf{2 0 0 5}$ & $\mathbf{2 0 1 1}$ \\
\hline Australia & 69,9 & 71 & 67 & 65,5 \\
Austria & 67,1 & 65,5 & 62,2 & 63,8 \\
Belgium & 69,5 & 68,4 & 64,6 & 64,9 \\
Czech Republic & 51,7 & 52,8 & 55,3 & 56,5 \\
Denmark & 65,8 & 67,2 & 69,2 & 70,2 \\
Estonia & 65,8 & 57,2 & 54,1 & 57,6 \\
Finland & 65,1 & 63,1 & 63,9 & 69,7 \\
France & 72,1 & 70,4 & 71,9 & 75,1 \\
Germany & 71,4 & 72,1 & 68,4 & 68,5 \\
Ireland & 54,9 & 49 & 48,5 & 46,2 \\
Italy & 64,2 & 63,5 & 66,7 & 71,1 \\
Japan & 74,5 & 72,2 & 67,6 & 68,9 \\
Korea & 74,4 & 67,2 & 67,7 & 62,3 \\
Netherlands & 73,9 & 71,6 & 67,9 & 68,8 \\
Norway & 65,7 & 69,9 & 64,5 & 67,6 \\
Slovak Republic & 48,4 & 55,5 & 51,4 & 52,1 \\
Spain & 64,5 & 65,7 & 64.6 & 66.9 \\
Sweden & 59.7 & 62.2 & 59.8 & 61.5 \\
United Kingdom & 70.1 & 73.6 & 72.2 & 75.1 \\
United States & 72 & 70.3 & 66.8 & 65.8 \\
\hline mean & 66.04 & 65.42 & 63.72 & 64.91 \\
sd & 7.39 & 6.98 & 6.63 & 7.30 \\
\hline Sonce: OECD Natin
\end{tabular}

Source: OECD National Accounts Database 
Figure 8: Labor Share - Data versus Simulation

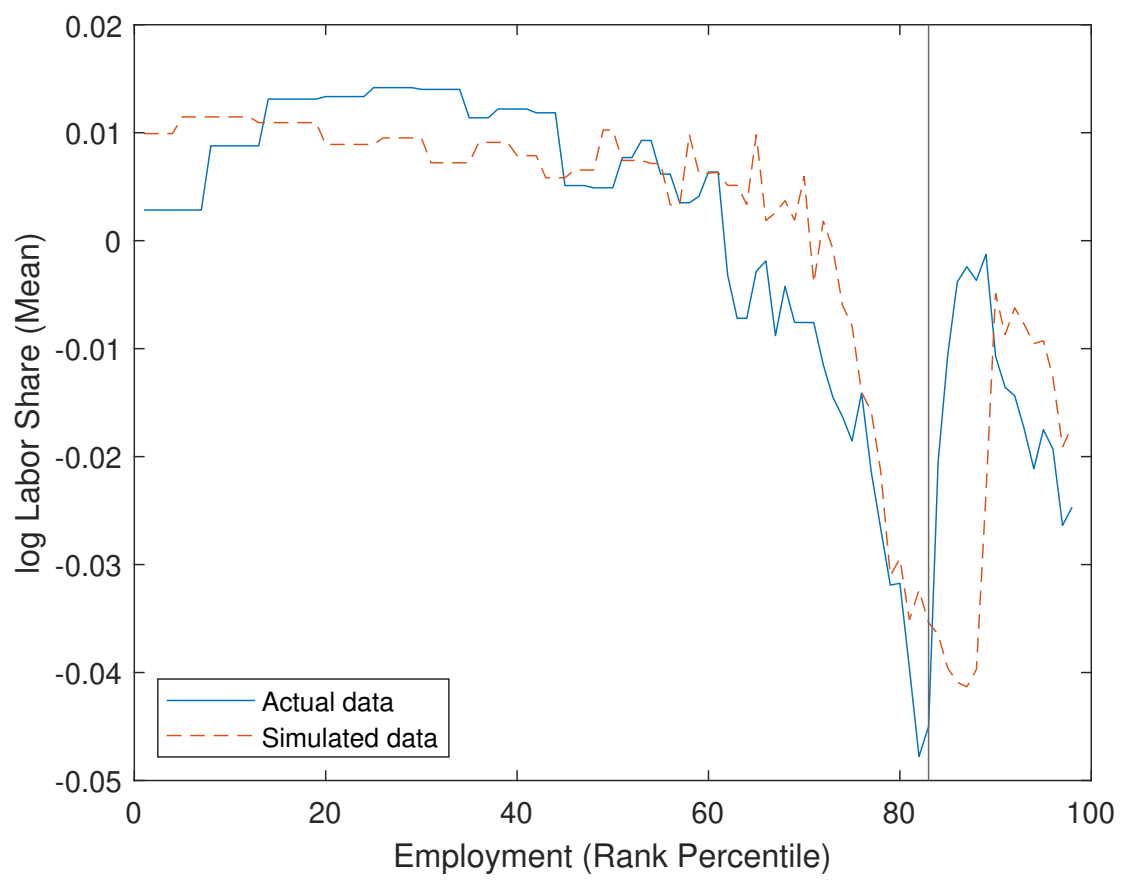

Notes: This figure depicts the mean log labor share by percentile of firm size, both in the data and in a sample simulated from the model. The simulated sample has the same size as the actual sample and is obtained using parameter values reported in table 3 The log labor share variable is de-meaned by 2-digit industry. Percentiles are computed using pooled data and the vertical bar corresponds to the 50 employees threshold.

difference between small and large firms, I fix $b=0$. The rest of the calibration procedure is identical. ${ }^{11}$ The results from this exercise are presented in panel $\mathrm{B}$ of table (5). As one can verify, there is no effect of correlated distortions on the labor share in this case. This shows that taking into account technological differences across firms, above and beyond TFP differences, matters to understand the macroeconomic consequences of heterogeneous policy distortions.

Let me now give a quick intution of the other results in table 5, panel A. The key variable to understand the response of wages is the aggregate profits to capital ratio, $\Pi / K$. Since small firms are less capital intensive, they have a larger profits to capital ratio. As distortions increase the weight of small firms in the economy, the aggregate profit to capital ratio increases, through a composition effect. Since $K$ is fixed, and $\Pi / K$ increases, it must be that the aggregate profits $\Pi$ increase. To maintain the free entry condition, wages must increase in return. This wage increase allows more firms to enter the economy by exerting a negative pressure on the average number of workers per firm.

In order to investigate the robustness of my results, I simulate the impact of taxing the $50 \%$ most productive firms without subsidizing the $50 \%$ least productive. The impact on the labor share, presented in table 7 , is slightly smaller than the one obtained table 5 , panel A. For instance, a $50 \%$ tax on output generates a 2 percentage points labor share increased when unproductive firms are subsidized, while this effect is only 1.88 percentage points when unproductive firms are

\footnotetext{
${ }^{11}$ The list of parameter values in this alternative calibration can be found in appendix $\mathrm{A}$
} 
Table 7: Correlated Distortions with Aggregate Capital Stock Adustment

\begin{tabular}{lrrrrr}
\hline tax rate $(\boldsymbol{\tau})$ & $\mathbf{1 0 . 0 0} \mathbf{\%}$ & $\mathbf{2 0 . 0 0} \%$ & $\mathbf{3 0 . 0 0} \%$ & $\mathbf{4 0 . 0 0} \%$ & $\mathbf{5 0 . 0 0} \boldsymbol{\%}$ \\
\hline subsidy rate $\left(\tau_{s}\right)$ & $0.00 \%$ & $0.00 \%$ & $0.00 \%$ & $0.00 \%$ & $0.00 \%$ \\
$\Delta$ GDP & $-4.99 \%$ & $-11.62 \%$ & $-20.50 \%$ & $-30.03 \%$ & $-36.99 \%$ \\
$\Delta$ Labor share & $0.29 \%$ & $0.81 \%$ & $1.55 \%$ & $2.25 \%$ & $2.65 \%$ \\
& $(0.21$ p.p. $)$ & $(0.57$ p.p. $)$ & $(1.09$ p.p. $)$ & $(1.58$ p.p. $)$ & $(1.87$ p.p.) \\
$\Delta$ mean firm size & $15.99 \%$ & $33.92 \%$ & $51.05 \%$ & $63.33 \%$ & $69.39 \%$ \\
$\Delta E$ & $-13.79 \%$ & $-25.33 \%$ & $-33.80 \%$ & $-38.77 \%$ & $-40.96 \%$ \\
$\Delta K$ & $-14.47 \%$ & $-26.96 \%$ & $-36.55 \%$ & $-42.46 \%$ & $-45.16 \%$ \\
$\Delta w$ & $-13.54 \%$ & $-24.72 \%$ & $-32.77 \%$ & $-37.40 \%$ & $-39.40 \%$ \\
$\Delta r$ & $0.00 \%$ & $0.00 \%$ & $0.00 \%$ & $0.00 \%$ & $0.00 \%$ \\
\hline
\end{tabular}

Notes: This table reports the effect of imposing a tax rate $\tau$ on the output of the $50 \%$ most productive firms. The rest of the firms are not subsidized.

not subsidized. These smaller effects can be easily explained: when unproductive firms are not subsidizied, the market share of high labor share firms expands less, which results in a smaller rise in the aggregate labor share.

Overall, this section shows that correlated distortions can generate sizable factor income re-distribution through between-firm capital-labor substitution. This is an important result as it implies that labor share movement can signal changes in the efficiency of resource allocation across firms.

\subsubsection{Capital Price Distortions}

In this section, I simulate the impact of heterogeneous distortions on the price of capital. In contrast to distortions on the price of output, distortions on capital price impact the relative cost of capital and labor. This will generate capital-labor substitution within firms on top of the capital-labor substitution between firms documented in previous section. One of my interests in this section is to see how the magnitude of these two types of factor substitution compare to each other.

I start my analysis by considering the case of uncorrelated capital distortions. The results, reported in table 8, reveal that taxing the capital of half the firms increases the aggregate labor share. This is simply due to taxed firms substituting labor for capital, which translates into a large drop in the aggregate stock of capital. To put numbers from table 8 in perspective, it is enlighting to compare them to those from table 7.

In both tables, $50 \%$ of firms are taxed. However, labor share changes from table 7 result purely from between-firm substitution (resources are reallocated toward unproductive/labor intensive firms), while they are entirely due to within-firm substitution in 8. Both effects appear to be of the same magnitude. This means that one obtains essentially the same factor income redistribution by distorting the relative price of factors between firms or within firms. This confirms the quantitative importance of the between-firm substitution that I document in this paper.

Next, I simulate correlated policy distortions on the price of capital, whereby the $50 \%$ most 
Table 8: Uncorrelated Capital Distortion with Aggregate Capital Stock Adjustment

\begin{tabular}{lrrrrr}
\hline tax rate $(\boldsymbol{\tau})$ & $\mathbf{1 0 . 0 0} \mathbf{\%}$ & $\mathbf{2 0 . 0 0} \mathbf{\%}$ & $\mathbf{3 0 . 0 0} \%$ & $\mathbf{4 0 . 0 0} \%$ & $\mathbf{5 0 . 0 0} \%$ \\
\hline subsidy rate $\left(\tau_{s}\right)$ & $0.00 \%$ & $0.00 \%$ & $0.00 \%$ & $0.00 \%$ & $0.00 \%$ \\
$\Delta$ GDP & $-1.70 \%$ & $-3.11 \%$ & $-4.29 \%$ & $-5.29 \%$ & $-6.14 \%$ \\
$\Delta$ Labor share & $1.12 \%$ & $1.91 \%$ & $2.46 \%$ & $2.83 \%$ & $3.07 \%$ \\
& $(0.79$ p.p.) & $(1.34$ p.p. $)$ & $(1.73$ p.p. $)$ & $(1.99$ p.p. $)$ & $(2.16$ p.p.) \\
$\Delta$ mean firm size & $1.73 \%$ & $3.21 \%$ & $4.48 \%$ & $5.58 \%$ & $6.54 \%$ \\
$\Delta E$ & $-1.70 \%$ & $-3.11 \%$ & $-4.29 \%$ & $-5.29 \%$ & $-6.14 \%$ \\
$\Delta K$ & $-5.84 \%$ & $-10.00 \%$ & $-13.00 \%$ & $-15.17 \%$ & $-16.74 \%$ \\
$\Delta w$ & $-1.69 \%$ & $-3.09 \%$ & $-4.27 \%$ & $-5.26 \%$ & $-6.11 \%$ \\
$\Delta r$ & $0.00 \%$ & $0.00 \%$ & $0.00 \%$ & $0.00 \%$ & $0.00 \%$ \\
\hline
\end{tabular}

Notes: This table reports the effect of imposing a tax rate $\tau$ on the capital of $50 \%$ of the firms.

Taxed firms are selected randomly, independently of their productivity.

productive firms get taxed. The results are reported in table 9. The effects on the labor share are about twice larger than those obtained with uncorrelated distortions. This raises the question of the mechanism: how much of the large labor share effects reported in table 9 is due to betweenfirm capital-labor substitution? In other words, how much is due to the fact that distortions redistribute market shares towards unproductive/high labor share firms?

The answer to this question can be found in panel B of table 9. These results were obtained by re-running the same policy simulations as in panel A but imposing $b=0$ so that all firms have the same labor share parameter $\alpha$ (the rest of the calibration procedure is identical in both panels). This operation amounts to shutting down any between-firm capital-labor substitution, which should mitigate the positive effect on the labor share. This is indeed what I find, however differences between panel A and B are small. For instance, for $\tau=50 \%$, the effect on the labor share drops from 5.77 p.p. to 5.48 p.p. (-5\%). In other words, taking into account factor share differences across firms is second order when it comes to quantifying the distributional effects of correlated capital distortions.

This finding may seem contradictory to results on correlated output distortion (section 4.2.1), in which factor share differences played a central role. This is because taxing capital triggers both less factor substitution between firms and more factor substitution within firms. ${ }^{12}$ Both effects contribute to reducing the importance of factor share differences across firms in the labor share response.

To summarize on table 9, the large effects of correlated capital distortions on the labor share result from the fact that (i) taxed firms substitute capital for labor and (ii) these taxed firms stand for a large share of the economy because they are the most productive ones.

The take-away message from this section is twofold: in order to quantify the labor share consequences of capital taxation it is important to take into account whether this taxation is correlated to firm productivity, but it is not important to take into account factor share

\footnotetext{
${ }^{12}$ The reason why capital taxation triggers less factor substitution between firms than output taxation is simple: capital costs only stand for a fraction of firm total production costs. Therefore, when capital costs of most productive firms increase due to taxation, it does not trigger a market share reallocation as strong as when output gets taxed. Less market share reallocation means less between-firm factor substitution.
} 
Table 9: Correlated Capital Distortions

\begin{tabular}{|c|c|c|c|c|c|}
\hline tax rate $(\tau)$ & $10.00 \%$ & $20.00 \%$ & $30.00 \%$ & $40.00 \%$ & $50.00 \%$ \\
\hline \multicolumn{6}{|c|}{ Panel A: Baseline Calibration } \\
\hline subsidy rate $\left(\tau_{s}\right)$ & $0.00 \%$ & $0.00 \%$ & $0.00 \%$ & $0.00 \%$ & $0.00 \%$ \\
\hline$\Delta \mathrm{GDP}$ & $-3.23 \%$ & $-6.04 \%$ & $-8.51 \%$ & $-10.71 \%$ & $-12.66 \%$ \\
\hline \multirow[t]{2}{*}{$\Delta$ Labor share } & $2.25 \%$ & $4.14 \%$ & $5.73 \%$ & $7.07 \%$ & $8.19 \%$ \\
\hline & (1.59 p.p.) & (2.92 p.p.) & (4.03 p.p.) & (4.97 p.p.) & (5.76 p.p.) \\
\hline$\Delta$ mean firm size & $3.34 \%$ & $6.43 \%$ & $9.30 \%$ & $11.99 \%$ & $14.50 \%$ \\
\hline$\Delta E$ & $-3.23 \%$ & $-6.04 \%$ & $-8.51 \%$ & $-10.71 \%$ & $-12.66 \%$ \\
\hline$\Delta K$ & $-11.28 \%$ & $-20.15 \%$ & $-27.23 \%$ & $-32.94 \%$ & $-37.60 \%$ \\
\hline$\Delta w$ & $-3.17 \%$ & $-5.93 \%$ & $-8.35 \%$ & $-10.49 \%$ & $-12.40 \%$ \\
\hline$\Delta r$ & $0.00 \%$ & $0.00 \%$ & $0.00 \%$ & $0.00 \%$ & $0.00 \%$ \\
\hline \multicolumn{6}{|c|}{ Panel B: $\operatorname{corr}(\varphi, \alpha)=0$} \\
\hline subsidy rate $\left(\tau_{s}\right)$ & $0.00 \%$ & $0.00 \%$ & $0.00 \%$ & $0.00 \%$ & $0.00 \%$ \\
\hline$\Delta \mathrm{GDP}$ & $-3.13 \%$ & $-5.86 \%$ & $-8.26 \%$ & $-10.39 \%$ & $-12.29 \%$ \\
\hline \multirow[t]{2}{*}{$\Delta$ Labor share } & $2.17 \%$ & $3.97 \%$ & $5.48 \%$ & $6.74 \%$ & $7.79 \%$ \\
\hline & (1.53 p.p.) & (2.80 p.p.) & (3.86 p.p.) & (4.75 p.p.) & (5.48 p.p.) \\
\hline$\Delta$ mean firm size & $3.23 \%$ & $6.22 \%$ & $9.00 \%$ & $11.59 \%$ & $14.01 \%$ \\
\hline$\Delta E$ & $-3.13 \%$ & $-5.86 \%$ & $-8.26 \%$ & $-10.39 \%$ & $-12.29 \%$ \\
\hline$\Delta K$ & $-10.95 \%$ & $-19.56 \%$ & $-26.41 \%$ & $-31.94 \%$ & $-36.43 \%$ \\
\hline$\Delta w$ & $-3.13 \%$ & $-5.86 \%$ & $-8.26 \%$ & $-10.39 \%$ & $-12.29 \%$ \\
\hline$\Delta r$ & $0.00 \%$ & $0.00 \%$ & $0.00 \%$ & $0.00 \%$ & $0.00 \%$ \\
\hline
\end{tabular}

Notes: This table reports the effect of imposing a tax rate $\tau$ on the capital of the $50 \%$ most productive firms. In panel A, I use benchmark calibration from table 3 In panel B, the model is calibrated as described in table 14 , imposing symmetric labor elasticity $\alpha$ across firms. 
differences across firms.

\subsubsection{Labor Price Distortions : The 50 employees threshold}

In this section I study the labor share effect of removing the 50 employees threshold (i.e. $\tau^{(n)}=$ $F=0)$. This effect is a priori ambiguous. On the one hand, removing the threshold reduces the relative cost of labor, which leads both bunching firms and regulated firms to substitute labor for capital. This within-firm substitution effect tends to increase the aggregate labor share. On the other hand, removing the threshold increases the weight of productive/low-labor share firms in the economy. This between-firm substitution effect tends to reduce the labor share.

Results from the above section on capital price distortions would suggest that the withinfirm effect dominates, so that labor share increases when removing the 50 threshold. This is indeed what I find as one can see from the column 1 of table 10. Results in column (2) were obtained under the alternative calibration $b=0$. In this case the labor share increases more because the negative effect of reallocating market shares toward capital intensive firms is shut down. However, when comparing columns (1) and (2), there is little difference in the labor share response: 0.43 p.p. versus 0.4 p.p. This confirms the result from previous section that in the case of correlated distortions on factor prices, factor share heterogeneity across firms plays a limited role.

Table 10: Removing the 50 Employees Threshold

\begin{tabular}{lrr}
\hline & \multicolumn{1}{c}{$(1)$} & \multicolumn{1}{c}{$(2)$} \\
& $\boldsymbol{c o r r}(\boldsymbol{\varphi}, \boldsymbol{\alpha})<\mathbf{0}$ & $\boldsymbol{\operatorname { c o r r }}(\boldsymbol{\varphi}, \boldsymbol{\alpha})=\mathbf{0}$ \\
\hline$\Delta$ GDP & $1.06 \%$ & $1.02 \%$ \\
$\Delta$ Labor share & $0.57 \%$ & $0.61 \%$ \\
& $(0.40$ p.p. $)$ & $(0.43$ p.p. $)$ \\
$\Delta$ mean firm size & $1.71 \%$ & $1.75 \%$ \\
$\Delta E$ & $-1.68 \%$ & $-1.72 \%$ \\
$\Delta K$ & $-0.10 \%$ & $-0.26 \%$ \\
$\Delta w$ & $1.64 \%$ & $1.63 \%$ \\
$\Delta r$ & $0.00 \%$ & $0.00 \%$ \\
\hline
\end{tabular}

Notes: This table reports the effect of removing the 50 employees threshold. Results from column (1) are obtained under the benchmark calibration (see table 3). By contrast, column (2) is obtained by imposing that labor elasticity $\alpha$ is symmetric across firms $(b=0)$.

\section{Sensitivity Analysis}

In this section, I investigate the sensitivity of my simulation results to alternative model calibrations and specifications. 


\subsection{The Role of Firm Selection}

When calibrating the model, I have assumed the absence of fixed operating costs: $c_{f}=0$. This implies that policy distortions redistribute resources across firms at the intensive margin but not at the extensive margin. By contrast, if I assumed that $c_{f}>0$, only most productive firms would survive upon entry. In this case, correlated policy distortions could also redistribute resources at the extensive margin, toward firms which would have not survived in a distortionfree equilibrium.

I investigate the consequences of such selection effects for the aggregate labor share in table 11. Results from this table were obtained by calibrating $c_{f}$ to match a $50 \%$ survival probability of entering firms upon entry. In other words, in the factual equilibrium, only half of the new firms are productive enough to be profitable and remain on the market. When compared to results from table 5. I find that taking into account selection can greatly magnify the effects on the labor share. For instance, the effect of a $50 \%$ tax on the most productive firms is doubled (it switches from 2p.p. to 3.96 p.p.). This is because in the presence of selection, correlated distortions allow more unproductive/ high labor share firms to survive, which translates at the aggregate level. These results reinforce the message of this paper : correlated output distortions can have large consequences on the aggregate labor share.

Table 11: Correlated Output Distortions with Endogenous Exit

\begin{tabular}{lrrrrr}
\hline subsidy rate $\left(\tau_{s}\right)$ & $38.26 \%$ & $42.97 \%$ & $44.63 \%$ & $45.19 \%$ & $45.34 \%$ \\
$\Delta$ GDP & $-14.61 \%$ & $-20.41 \%$ & $-23.19 \%$ & $-24.39 \%$ & $-24.81 \%$ \\
$\Delta$ Labor share & $4.60 \%$ & $5.26 \%$ & $5.51 \%$ & $5.60 \%$ & $5.63 \%$ \\
& $(3.22$ p.p. $)$ & $(3.68$ p.p. $)$ & $(3.86$ p.p. $)$ & $(3.92$ p.p. $)$ & $(3.94$ p.p. $)$ \\
$\Delta$ mean firm size & $-43.65 \%$ & $-41.01 \%$ & $-39.78 \%$ & $-39.24 \%$ & $-39.02 \%$ \\
$\Delta E$ & $2.18 \%$ & $6.20 \%$ & $7.83 \%$ & $8.46 \%$ & $8.67 \%$ \\
$\Delta K$ & $0.00 \%$ & $0.00 \%$ & $0.00 \%$ & $0.00 \%$ & $0.00 \%$ \\
$\Delta w$ & $17.43 \%$ & $20.71 \%$ & $22.01 \%$ & $22.48 \%$ & $22.61 \%$ \\
$\Delta r$ & $0.00 \%$ & $0.00 \%$ & $0.00 \%$ & $0.00 \%$ & $0.00 \%$ \\
$\Delta$ survival & $73.68 \%$ & $59.62 \%$ & $53.99 \%$ & $51.74 \%$ & $50.92 \%$ \\
& $(36.74$ p.p. $)$ & $(29.73$ p.p. $)$ & $(26.92$ p.p. $)$ & $(25.80$ p.p. $)$ & $(25.39$ p.p. $)$ \\
\hline
\end{tabular}

Notes: This table reports the effect of imposing a tax rate $\tau$ on the output of the $50 \%$ most productive firms. The steady-state capital stock is kept constant through a subsidy on the output of the least productive firms. The value of fixed cost $c_{f}$ is calibrated to match a $50 \%$ survival probability of firms upon entry. These resuts are to be compared to those from table 5 panel A, which correspond to the same policy experiment, but calibrating $c_{f}=0$.

\subsection{Alternative Model Calibrations : Pooled versus Within-Industry Data}

Parameter $b$ is central to my analysis since it drives the slope of the firm-level relationship between productivity and labor share. So far, I have calibrated $b$ by matching the size - labor share relationship within 2-digit industries. In this paragraph, I investigate the sensitivity of my results using two different levels of industry disaggregation to calibrate the model. Specifically, I use labor variation from the pooled data in one case and within 4-digit industries in the other. 
Figure 9: Labor Share - Size Relationship under Alternative Construction Rules
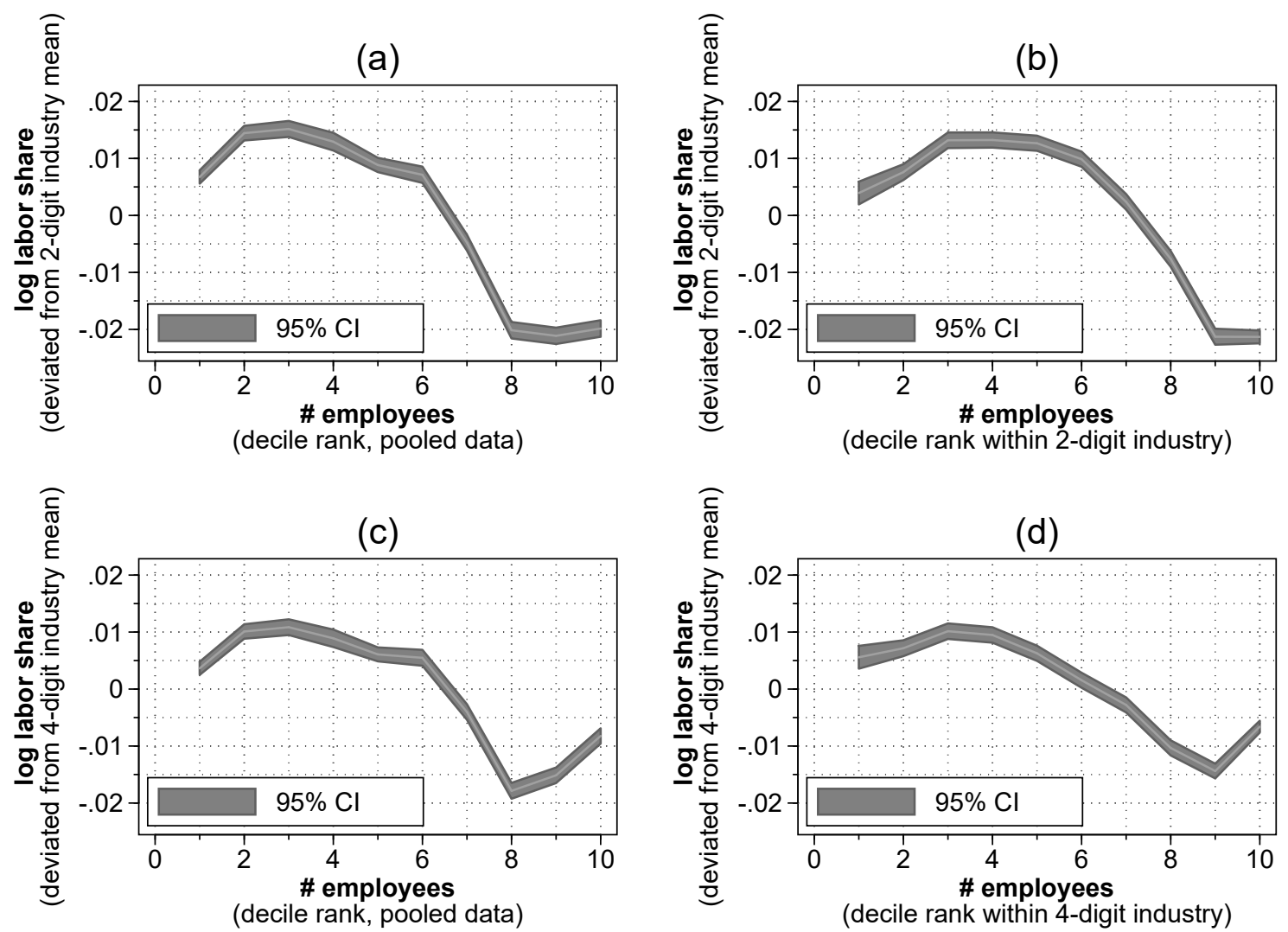

Notes: Each one of these four panels depicts the average log labor share by decile of firm size. To obtain these figures, the log labor share is de-meaned at the 2-digit industry level for panels (a) and (b) (respectively at the 4-digit industry level for (c) and (d)). Decile ranks are constructed as follows: from pooled data in panels (a) and (c), by 2-digit industry in (b) and by 4-digit industry in (d).

Figure 9 depicts the labor share - size relationship at different levels of industry disaggregation. Comparing the different panels of figure 2 reveals that centering the log labor share data at a finer level and constructing size quantiles by industry both contribute to flattening the relationship. However, larger firms remain significantly less labor intensive: in panel (d) which corresponds to the most conservative approach - the average labor share difference above median and below median is $-1.4 \%$.

From a conceptual standpoint, the 4-digit calibration is quite conservative since it amounts to assuming away any factor re-allocation between 4-digit industries (be they within the same 2digit industry or not). On the contrary, calibrating the model from pooled data seems excessively liberal since it is equivalent to assuming zero friction to factor re-allocation across industries. Therefore one can see these two approaches as a lower bound and upper bound on the potential labor share effects of heterogeneous distortions. 
The results from this sensitivity analysis are presented in table 12. More specifically, table 12 reports the effect of imposing a tax rate $\tau$ on the output of the $50 \%$ most productive firms. The steady-state capital stock is kept constant through a subsidy $\tau_{s}$ on the output of the least productive firms. Throughout all columns, parameter $b$ - which governs the productivity-labor intensity relationship in the model - is calibrated to match the difference in the average log labor share above and below median firm size. The exact way in which this difference is computed differs across columns: Log labor shares are de-meaned at the 4-digit industry level in column (1) and at the 2-digit level in column (2); Median firm size is computed by 4-digit industry in column (1), by 2-digit industry in column (2) and from pooled data in column (3).

The magnitude of parameter $b$ increases as one moves to the right of the table because the model is matching an increasingly steep size-labor share relationship. Consequently, the labor share impact of the distortions also increases. In column 3 (pooled data calibration) the aggregate labor share response stands between 1.63 p.p. and 4.45 p.p.. By contrast, when I calibrate my model using the most conservative approach (within 4-digit calibration - column 1), I still obtain a sizable response, ranging from 0.59 p.p. to 2.80 p.p..

To put these numbers in perspective, the labor share in France was 5 p.p. larger than in the US in 2005.5 p.p. also corresponds to the global drop in the labor share over the past 30 years, as estimated by Karabarbounis and Neiman (2014). The most restrictive simulations suggest that the removal of productivity-based output distortions could explain from $12 \%$ to $56 \%$ of this evolution.

\subsection{Sensitivity to $\theta$ Parameter}

As a last sensitivity exercise, I investigate how my results change when changing the value of returns to scale $\theta$. This parameter drives the elasticity of firm-level output to taxes: the larger $\theta$, the more heterogeneous price distortions reallocate market shares across firms. Therefore, the larger $\theta$, the larger should be the impact of correlated output distortion on the labor share.

Table 13 reports the labor share response to correlated output distortions for different values of $\theta$. For each value, all model parameters are re-calibrated following procedure described in calibration table 3. Results from 13 confirm that $\theta$ matters for the labor share response. However, even with a value of $\theta$ of 0.5 - a low value for the misallocation literature - I still get a sizable effect on the labor share. More specifically, moving from $\theta=0.86$ (my prefered value) to $\theta=0.5$ reduces the labor share response from 2 p.p. to 1.56 p.p., which corresponds to a $22 \%$ reduction.

\section{Conclusion}

In this paper, I study the labor share impact of heterogenous policy distortions on the labor share of national income. To this end, I develop an extension of the Neoclassical growth model with two-way heterogeneity: firm production functions differ both in terms of TFP and labor elasticity. In this model, productivity-based and size-based government policies are likely to impact the aggregate labor share by redistributing market shares toward labor intensive firms.

Using firm-level production data for France, I show that this effect can be substantial, especially in the case of distortions in the price of output. Depending on the calibration of the model, this effect ranges from 1 to 4 percentage points. This is quantitatively comparable to 
Table 12: Correlated Output Distortions and the Labor Share - Alternative Model Calibrations

\begin{tabular}{lccc}
\hline tax rate $(\boldsymbol{\tau})$ & $(1)$ & $(2)$ & $(3)$ \\
\hline $\mathbf{1 0 . 0 0} \%$ & 0.59 p.p. & 1.30 p.p. & 1.63 p.p. \\
& $(2.17$ p.p. $)$ & $(3.22$ p.p. $)$ & $(3.72$ p.p. $)$ \\
$\mathbf{2 0 . 0 0 \%}$ & 0.83 p.p. & 1.73 p.p. & 2.11 p.p. \\
& $(2.57$ p.p. $)$ & $(3.68$ p.p. $)$ & $(4.19$ p.p. $)$ \\
$\mathbf{3 0 . 0 0 \%}$ & 0.94 p.p. & 1.90 p.p. & 2.30 p.p. \\
& $(2.72$ p.p. $)$ & $(3.86$ p.p. $)$ & $(4.36$ p.p. $)$ \\
$\mathbf{4 0 . 0 0 \%}$ & 0.98 p.p. & 1.96 p.p. & 2.37 p.p. \\
& $(2.78$ p.p. $)$ & $(3.92$ p.p. $)$ & $(4.43$ p.p. $)$ \\
$\mathbf{5 0 . 0 0 \%}$ & 1.00 p.p. & 1.99 p.p. & 2.40 p.p. \\
& $(2.80$ p.p. $)$ & $(3.94$ p.p. $)$ & $(4.45$ p.p. $)$ \\
\hline Industry Level & 4 -digit & 2 -digit & Pooled \\
\hline
\end{tabular}

Notes: This table reports the effect of imposing a tax rate $\tau$ on the output of the $50 \%$ most productive firms. The steady-state capital stock is kept constant through a subsidy $\tau_{s}$ on the output of the least productive firms. The effect is expressed in percentage point change of the aggregate labor share, with respect to the distortionfree equilibrium. Numbers in parenthesis are obtained by allowing for endogenous firm selection. Throughout all columns, parameter $b$ - which governs the productivity-labor intensity relationship in the model - is calibrated to match the difference in the average log labor share above and below median firm size. The exact way in which this difference is computed differs across columns: Log labor shares are de-meaned at the 4-digit industry level in column (1) and at the 2-digit level in column (2); Median firm size is computed by 4-digit industry in column (1), by 2-digit industry in column (2) and from pooled data in column (3). 
Table 13: Sensitivity to $\theta$ of the Labor Share Response

\begin{tabular}{rrrrrr}
\hline & $\tau=10 \%$ & $\tau=20 \%$ & $\tau=30 \%$ & $\tau=40 \%$ & $\tau=50 \%$ \\
\hline$\theta=0.5$ & $0.62 \%$ & $1.13 \%$ & $1.56 \%$ & $1.92 \%$ & $2.21 \%$ \\
& $(0.44$ p.p. $)$ & $(0.8$ p.p. $)$ & $(1.1$ p.p. $)$ & $(1.35$ p.p. $)$ & $(1.56$ p.p. $)$ \\
$\theta=0.6$ & $0.75 \%$ & $1.33 \%$ & $1.78 \%$ & $2.13 \%$ & $2.39 \%$ \\
& $(0.53$ p.p. $)$ & $(0.94$ p.p. $)$ & $(1.26$ p.p. $)$ & $(1.50$ p.p. $)$ & $(1.68$ p.p. $)$ \\
$\theta=0.7$ & $0.94 \%$ & $1.57 \%$ & $2.01 \%$ & $2.30 \%$ & $2.49 \%$ \\
& $(0.66$ p.p. $)$ & $(1.11$ p.p. $)$ & $(1.41$ p.p. $)$ & $(1.62$ p.p. $)$ & $(1.76$ p.p. $)$ \\
$\theta=0.8$ & $1.40 \%$ & $2.10 \%$ & $2.47 \%$ & $2.66 \%$ & $2.76 \%$ \\
& $(0.99$ p.p. $)$ & $(1.48$ p.p. $)$ & $(1.74$ p.p. $)$ & $(1.87$ p.p. $)$ & $(1.94$ p.p. $)$ \\
$\theta=0.86$ & $1.85 \%$ & $2.45 \%$ & $2.69 \%$ & $2.79 \%$ & $2.82 \%$ \\
& $(1.30$ p.p. $)$ & $(1.73$ p.p. $)$ & $(1.90$ p.p. $)$ & $(1.96$ p.p. $)$ & $(1.99$ p.p. $)$ \\
\hline
\end{tabular}

Notes: This table reports, for different values of returns to scale parameter $\theta$, the effect of imposing a tax rate $\tau$ on the output of the $50 \%$ most productive firms. The steadystate capital stock is kept constant through a subsidy on the output of the least productive firms. For each value of $\theta$, I re-calibrate the whole model to match moments from table 3 .

the decline of the labor share observed in the world over the past decades. In other words, this decline could have been generated by a gradual removal of productivity/size-based distortions at the global level.

Testing whether the observed labor share decline actually results from a better allocation of resources across firms would require a time-country measure of distortions that could be correlated to labor share movements across countries and over time. Although this is beyond the scope of this paper, I see this exercise as a promising avenue for future research. 


\section{References}

Aghion, P., A. Bergeaud, T. Boppart, and S. Bunel (2018): "Firm dynamics and growth measurement in france," Journal of the European Economic Association, 16, 933-956.

Autor, D., D. Dorn, L. Katz, C. Patterson, and J. Van Reenen (2017): "The Fall of the Labor Share and the Rise of Superstar Firms (No. dp1482)," Centre for Economic Performance, LSE.

BAQAEE, D. R. AND E. FARHI (2020): "Productivity and misallocation in general equilibrium," The Quarterly Journal of Economics, 135, 105-163.

Blanchard, O. AND F. Giavazzi (2003): "Macroeconomic effects of regulation and deregulation in goods and labor markets," The Quarterly journal of economics, 118, 879-907.

Braguinsky, S., L. G. Branstetter, and A. Regateiro (2011): "The incredible shrinking Portuguese firm," Tech. rep., National Bureau of Economic Research.

De Loecker, J. And J. Eeckhout (2017): "The rise of market power and the macroeconomic implications," Tech. rep., National Bureau of Economic Research.

- (2018): "Global market power," Tech. rep., National Bureau of Economic Research.

Elsby, M. W., B. HobiJn, And A. ŞAHIN (2013): "The decline of the US labor share," Brookings Papers on Economic Activity, 2013, 1-63.

Garcia-Santana, M. And J. Pijoan-Mas (2014): "The reservation laws in India and the misallocation of production factors," Journal of monetary economics, 66, 193-209.

Garicano, L., C. Lelarge, and J. Van Reenen (2016): "Firm size distortions and the productivity distribution: Evidence from France," The American Economic Review, 106, 34393479 .

Gouin-Bonenfant, E. (2018): "Productivity dispersion, between-firm competition, and the labor share," .

Gourio, F. AND N. Roys (2014): "Size-dependent regulations, firm size distribution, and reallocation," Quantitative Economics, 5, 377-416.

Guner, N., G. Ventura, And Y. Xu (2008): "Macroeconomic implications of size-dependent policies," Review of Economic Dynamics, 11, 721-744.

Hopenhayn, H. and R. Rogerson (1993): "Job turnover and policy evaluation: A general equilibrium analysis," Journal of political Economy, 101, 915-938.

Hopenhayn, H. A. (1992): "Entry, exit, and firm dynamics in long run equilibrium," Econometrica: Journal of the Econometric Society, 1127-1150.

Hsien, C. AND P. KLenow (2009): "Misallocation and manufacturing TFP in China and India," The Quarterly Journal of Economics, 124, 1403.

Karabarbounis, L. and B. Neiman (2013): "The global decline of the labor share," The Quarterly journal of economics, 129, 61-103.

- (2014): "The global decline of the labor share," The Quarterly Journal of Economics, 129, 61-103.

Kehrig, M. AND N. Vincent (2017): "Growing productivity without growing wages: The micro-level anatomy of the aggregate labor share decline," Economic Research Initiatives at Duke (ERID) Working Paper.

Lashkari, D., A. Bauer, And J. Boussard (2018): "Information technology and returns to scale," Available at SSRN 3458604.

LucAs, R. (1978): "On the size distribution of business firms," The Bell Journal of Economics, 
$508-523$.

Oberfield, E. And D. Raval (2014): "Micro data and macro technology," Tech. rep., National Bureau of Economic Research.

Raval, D. (2011): "Estimation of a CES Production Function with Factor Augmenting Technology," Tech. rep., mimeo.

Restuccia, D. And R. Rogerson (2008): "Policy distortions and aggregate productivity with heterogeneous establishments," Review of Economic Dynamics, 11, 707-720.

(2013): "Misallocation and productivity," Review of Economic Dynamics, 16, 1-10.

(2017): "The causes and costs of misallocation," Journal of Economic Perspectives, 31, $151-74$.

Salomons, A. And D. Autor (2018): "Is automation labor-displacing? Productivity growth, employment, and the labor share," Tech. rep., National Bureau of Economic Research. 


\section{APPENDICES}

\section{A Symmetric Labor Elasticities}

This appendix section reports the value of the calibrated parameters obtained when imposing symmetric labor elasticity $\alpha$ across firms (see table 14). It also documents how the model fits the data under this calibration (figure 10).

Table 14: Calibration with Symmetric Labor Elasticities $(b=0)$

\begin{tabular}{lcc}
\hline parameter & value & target/source \\
\hline$\delta$ & 0.08 & $\frac{X}{G D P}=21 \%$ \\
$\beta$ & 0.96 & $R=4 \%$ \\
$\lambda$ & $13 \%$ & annual exit rate \\
$\theta$ & 0.86 & Garicano et al. $(2016)$ \\
$c_{f}$ & 0 & fixed \\
$c_{e}$ & 1 & fixed \\
$a$ & 0.99 & Mean log labor share \\
$b$ & 0 & fixed \\
$\varphi$ & 0.058 & $n(\varphi)=10$ \\
$\overline{\bar{\varphi}}$ & 0.154 & $n(\bar{\varphi})=10,000$ \\
$\kappa$ & 7.10 & Median firm size \\
$\tau^{(n)}$ & 0.023 & Garicano et al. 2016$)$ \\
$F$ & 0 & fixed \\
\hline
\end{tabular}

Notes : This table lists the targets (or sources) used in the calibration of the model from appendix section A along with the value obtained for the corresponding parameter. Parameter $b$ is set to zero which amounts to assuming no variation in labor intensity $\alpha$ across firms.

\section{B Fixed Regulatory Cost}

This appendix section reports the value of the calibrated parameters obtained when setting the value of the fixed regulatory cost $F$ from Garicano et al. (2016) (table 15). It also documents how the model fits the data under this calibration (figure 11a). I also present the effects of different policy experiments under this calibration. Specifically, tables 16 and 17 display the effects of correlated distortions on output and capital, respectively. Table 18 presents the effect of removing the 50 employees threshold. 
Figure 10: Actual versus Simulated Data with Symmetric Labor Elasticities $(b=0)$

(a) Firm Size Distribution

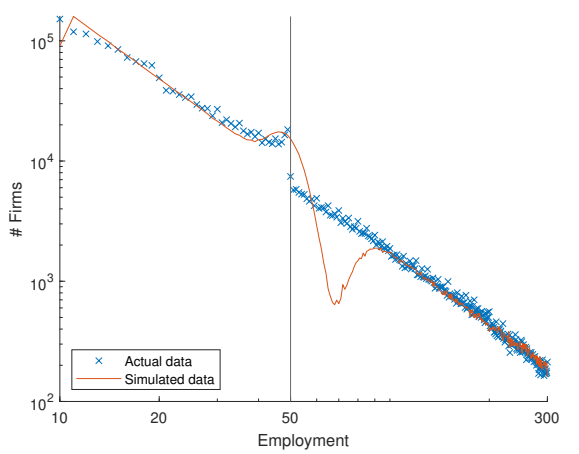

(b) Labor Share

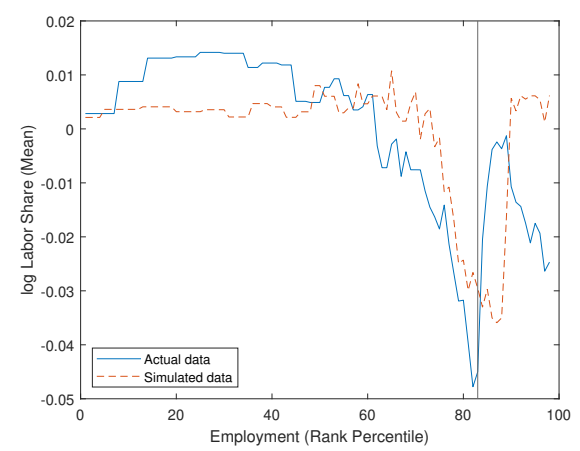

Notes: This figure depicts the firm size density (panel a) and the size-labor share relationship (panel b), both in the data and in a sample simulated from the model. The simulated sample has the same size as the actual sample and is obtained using parameter values reported in table 14 . The log labor share variable is de-meaned by 2-digit industry. Percentiles are computed using pooled data and the vertical bar corresponds to the 50 employees threshold.

Table 15: Calibration with a Fixed Regulatory Cost $(F \neq 0)$

\begin{tabular}{lcc}
\hline parameter & value & target/source \\
\hline$\delta$ & 0.08 & $X$ \\
$\beta$ & 0.96 & $R=4 \%$ \\
$\lambda$ & $13 \%$ & annual exit rate \\
$\theta$ & 0.86 & Garicano et al. $(2016)$ \\
$c_{f}$ & 0 & fixed \\
$c_{e}$ & 1 & fixed \\
$a$ & 1.14 & Mean log labor share \\
$b$ & -0.31 & fixed \\
$\varphi$ & 0.051 & $n(\underline{\varphi})=10$ \\
$\overline{\bar{\varphi}}$ & 0.169 & $n(\bar{\varphi})=10,000$ \\
$\kappa$ & 5.85 & Median firm size \\
$\tau$ & 0.023 & Garicano et al. $(2016)$ \\
$F$ & -0.941 & Garicano et al. $(2016)$ \\
\hline
\end{tabular}

Notes : This table lists the targets (or sources) used in the calibration of the model from appendix section $B$, along with the value obtained for the corresponding parameter. Parameter $b$ is calibrated to match the above median/below median difference in the mean log labor share within 2-digit industries (i.e., log labor shares are demeaned by industry and the median size is industry-specific). 
Figure 11: Actual versus Simulated Data with a Fixed Regulatory Cost $(F \neq 0)$

(a) Firm Size Distribution

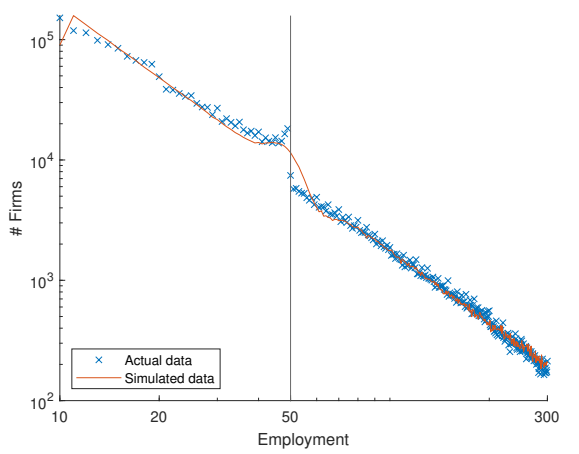

(b) Labor Share

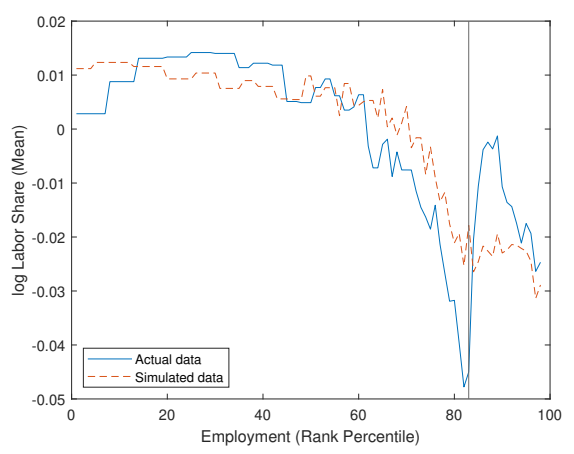

Notes: This figure depicts the firm size density (panel a) and the size-labor share relationship (panel b), both in the data and in a sample simulated from the model. The simulated sample has the same size as the actual sample and is obtained using parameter values reported in table 15 . The log labor share variable is de-meaned by 2-digit industry. Percentiles are computed using pooled data and the vertical bar corresponds to the 50 employees threshold.

Table 16: Correlated Output Distortions with a Fixed Regulatory Cost

\begin{tabular}{lrrrrr}
\hline tax rate $(\boldsymbol{\tau})$ & $\mathbf{1 0 . 0 0} \mathbf{\%}$ & $\mathbf{2 0 . 0 0} \%$ & $\mathbf{3 0 . 0 0} \%$ & $\mathbf{4 0 . 0 0} \%$ & $\mathbf{5 0 . 0 0} \mathbf{\%}$ \\
\hline subsidy rate $\left(\tau_{s}\right)$ & $42.28 \%$ & $49.18 \%$ & $51.75 \%$ & $52.73 \%$ & $53.08 \%$ \\
$\Delta$ GDP & $-14.79 \%$ & $-23.33 \%$ & $-27.96 \%$ & $-30.35 \%$ & $-31.47 \%$ \\
$\Delta$ Labor share & $2.68 \%$ & $3.40 \%$ & $3.68 \%$ & $3.79 \%$ & $3.83 \%$ \\
& $(1.88$ p.p. $)$ & $(2.39$ p.p. $)$ & $(2.59$ p.p. $)$ & $(2.66$ p.p. $)$ & $(2.69$ p.p. $)$ \\
$\Delta$ mean firm size & $-7.16 \%$ & $-9.08 \%$ & $-9.83 \%$ & $-10.12 \%$ & $-10.22 \%$ \\
$\Delta E$ & $7.71 \%$ & $9.98 \%$ & $10.90 \%$ & $11.26 \%$ & $11.39 \%$ \\
$\Delta K$ & $0.00 \%$ & $0.00 \%$ & $0.00 \%$ & $0.00 \%$ & $0.00 \%$ \\
$\Delta w$ & $10.59 \%$ & $13.72 \%$ & $14.98 \%$ & $15.47 \%$ & $15.65 \%$ \\
$\Delta r$ & $0.00 \%$ & $0.00 \%$ & $0.00 \%$ & $0.00 \%$ & $0.00 \%$ \\
\hline
\end{tabular}

Notes: This table reports the effect of imposing a tax rate $\tau$ on the output of the $50 \%$ most productive firms. The steady-state capital stock is kept constant through a subsidy $\tau_{s}$ on the output of the least productive firms. The model is calibrated as described in table 15, i.e. considering the fixed cost component of the 50 threshold. 
Table 17: Correlated Capital Distortions with a Fixed Regulatory Cost

\begin{tabular}{lrrrrr}
\hline tax rate $(\boldsymbol{\tau})$ & $\mathbf{1 0 . 0 0} \mathbf{\%}$ & $\mathbf{2 0 . 0 0} \%$ & $\mathbf{3 0 . 0 0} \%$ & $\mathbf{4 0 . 0 0} \%$ & $\mathbf{5 0 . 0 0} \mathbf{\%}$ \\
\hline subsidy rate $\left(\tau_{s}\right)$ & $0.00 \%$ & $0.00 \%$ & $0.00 \%$ & $0.00 \%$ & $0.00 \%$ \\
$\Delta$ GDP & $-3.27 \%$ & $-6.12 \%$ & $-8.63 \%$ & $-10.85 \%$ & $-12.83 \%$ \\
$\Delta$ Labor share & $2.29 \%$ & $4.22 \%$ & $5.84 \%$ & $7.21 \%$ & $8.36 \%$ \\
& $(1.61$ p.p. $)$ & $(2.97$ p.p. $)$ & $(4.11$ p.p. $)$ & $(5.07$ p.p. $)$ & $(5.88$ p.p.) \\
$\Delta$ mean firm size & $3.39 \%$ & $6.52 \%$ & $9.44 \%$ & $12.17 \%$ & $14.72 \%$ \\
$\Delta E$ & $-3.27 \%$ & $-6.12 \%$ & $-8.63 \%$ & $-10.85 \%$ & $-12.83 \%$ \\
$\Delta K$ & $-11.42 \%$ & $-20.40 \%$ & $-27.56 \%$ & $-33.34 \%$ & $-38.05 \%$ \\
$\Delta w$ & $-3.19 \%$ & $-5.96 \%$ & $-8.39 \%$ & $-10.54 \%$ & $-12.45 \%$ \\
$\Delta r$ & $0.00 \%$ & $0.00 \%$ & $0.00 \%$ & $0.00 \%$ & $0.00 \%$ \\
\hline
\end{tabular}

Notes: This table reports the effect of imposing a tax rate $\tau$ on the capital of the $50 \%$ most productive firms. The model is calibrated as described in table 15, i.e. considering the fixed cost component of the 50 threshold.

Table 18: Removal of the 50 Employees Threshold with a Fixed Regulatory Cost

\begin{tabular}{lrr}
\hline & \multicolumn{1}{c}{$(1)$} & \multicolumn{1}{c}{$(2)$} \\
& $\boldsymbol{c o r r}(\boldsymbol{\varphi}, \boldsymbol{\alpha})<\mathbf{0}$ & $\boldsymbol{\operatorname { c o r r }}(\boldsymbol{\varphi}, \boldsymbol{\alpha})=\mathbf{0}$ \\
\hline$\Delta$ GDP & $0.88 \%$ & $0.97 \%$ \\
$\Delta$ Labor share & $0.57 \%$ & $0.51 \%$ \\
& $(0.40$ p.p. $)$ & $(0.36$ p.p. $)$ \\
$\Delta$ mean firm size & $1.78 \%$ & $1.53 \%$ \\
$\Delta E$ & $-1.75 \%$ & $-1.51 \%$ \\
$\Delta K$ & $-0.30 \%$ & $0.00 \%$ \\
$\Delta w$ & $1.45 \%$ & $1.49 \%$ \\
$\Delta r$ & $0.00 \%$ & $0.00 \%$ \\
\hline
\end{tabular}

Notes: This table reports the effect of removing the 50 employees threshold. Results from column (1) are obtained under the calibration from table 15 By contrast, column (2) is obtained by imposing that labor elasticity $\alpha$ is symmetric across firms $(b=0)$. 